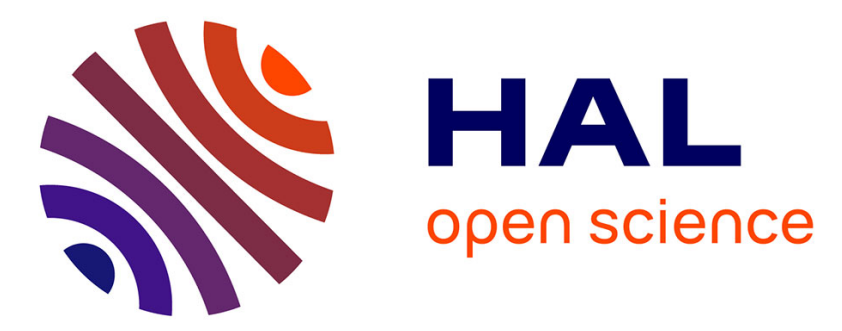

\title{
Molecular dynamics simulation-based study of creep-ratcheting behavior of nanocrystalline aluminum
}

Pokula Narendra Babu, Charlotte Becquart, Snehanshu Pal

\section{To cite this version:}

Pokula Narendra Babu, Charlotte Becquart, Snehanshu Pal. Molecular dynamics simulation-based study of creep-ratcheting behavior of nanocrystalline aluminum. Applied Nanoscience, 2020, Applied Nanoscience, 10.1007/s13204-020-01595-5 . hal-03006862

\section{HAL Id: hal-03006862 \\ https://hal.univ-lille.fr/hal-03006862}

Submitted on 16 Nov 2020

HAL is a multi-disciplinary open access archive for the deposit and dissemination of scientific research documents, whether they are published or not. The documents may come from teaching and research institutions in France or abroad, or from public or private research centers.
L'archive ouverte pluridisciplinaire HAL, est destinée au dépôt et à la diffusion de documents scientifiques de niveau recherche, publiés ou non, émanant des établissements d'enseignement et de recherche français ou étrangers, des laboratoires publics ou privés. 


\title{
Molecular Dynamics Simulation Based Study of Creep-Ratcheting Behavior of
} Nanocrystalline Aluminum

\author{
Pokula Narendra Babu ${ }^{\mathrm{a} 1}$, Charlotte S. Becquart ${ }^{\mathrm{b}}$, Snehanshu Pal ${ }^{\mathrm{a} 1, \mathrm{a2} *}$ \\ ${ }^{a 1}$ Department of Metallurgical and Materials Engineering, National Institute of Technology Rourkela, Rourkela \\ - 769008, India \\ ${ }^{a 2}$ Centre of Nanomaterials, National Institute of Technology Rourkela, Rourkela - 769008, India \\ bUniv. Lille, CNRS, INRAE, Centrale Lille, UMR 8207 - UMET - Unité Matériaux et Transformations, F- \\ 59000 Lille, France \\ *Corresponding author: Snehanshu Pal; E-mail address: snehanshu.pal@gmail.com; pals@nitrkl.ac.in. Phone \\ No. +91-661-2462573.
}

\begin{abstract}
In the present study, molecular dynamics simulations have been performed to investigate the creep-ratcheting deformation behavior of nanocrystalline aluminum ( $\mathrm{NC} \mathrm{Al}$ ) having an average grain size of $\sim 8 \mathrm{~nm}$. The influence of deformation temperature on creep-ratcheting behavior has been studied and associated with underlying mechanisms based on the structural evolution of the material identified. The vacancy concentrations, strains and dislocation densities have been evaluated at the end of each stage of creep-ratcheting process for two ratcheting stress ratios and three different temperatures. In the mean time, the microstructural and defect evolution has been investigated. Accumulation of creep-ratcheting strain is found to increase with the deformation temperature in the range of temperature investigated: $10 \mathrm{~K}-467 \mathrm{~K}$. Cyclic hardening dominates in the initial stages of creep-ratcheting, whereas cyclic softening dominates in the final stages at a higher temperature. The creep-ratcheting plots exhibit a primary and steady state regions at room temperature (300 K). In addition, a tertiary region is also perceived at high temperature $(467 \mathrm{~K})$. The $\mathrm{NC} \mathrm{Al}$ specimen is also found to be damaged earlier at a higher temperature (i.e., $467 \mathrm{~K}$ ) than at $10 \mathrm{~K}$ and $300 \mathrm{~K}$. The highest dislocation density is attained for room temperature creep-ratcheting deformation. Finally, it is seen from the dislocation analysis that the Shockley partial and full dislocations are the driving dislocations for the creep-ratcheting deformation process.
\end{abstract}

Keywords: Nanocrystalline aluminum; Creep; Ratcheting; Molecular dynamics; Dislocation 


\section{Introduction}

Nanocrystalline (NC) materials have a grain size of less than $100 \mathrm{~nm}$ ranges. They have a resilient flair towards structural applications due to their outstanding mechanical properties in contrast to conventional polycrystalline materials $[1,2,3,4,5,6]$. NC materials exhibit higher strength as a result of the triple junction's existence and a higher volume percentage of grain boundaries compared to polycrystalline materials $[7,8,9,10$, 11, 12]. They also exhibit different creep properties compared to bulk materials due to their triple junctions and grain boundaries. Creep is well-known as a time-dependent plastic deformation process occurring at constant stress/load. Creep deformation mechanisms have influenced by many parameters such as grain size, stress applied on the specimen, operative temperatures, etc. $[13,14,15,16,17]$. In nanocrystalline materials, the creep deformation is primarily caused by the diffusion process either with the aid of grain boundaries or in the bulk lattice $[18,19,20]$. Kong et al. have shown experimentally that creep mechanisms of nanocrystalline alloys (FeB-Si and Ni-P) are influenced by the grain size [21]. Petegem et al. have performed a creep study on nanocrystalline $\mathrm{Ni}$ and observed two different mechanisms for creep deformation [22]. In the first mechanism, the strain is caused owing to dislocation propagation; in the other mechanism, the strain is created by grain boundary accommodation.

Ratcheting is a progressive accumulation of plastic deformation processes observed in materials and structures during cyclic loading with non-zero mean stress, where the applied stresses are higher than materials yield stress $[23,24,25,26,27,28]$. It is one of the critical factors that must have considered concerning the design of structural components. Srinivasan et al. have experimentally investigated the effect of accumulated ratcheting strain on Al 7075-T6 alloys through the low cycle fatigue process [29]. They reported that ratcheting strain increases when the stress amplitude increases and ratcheting deformation happens mainly with the aid of back stress [29]. On the other hand, Kreethi et al. performed the ratcheting and post-ratcheting tensile tests with different mean stresses and stress amplitudes on commercial aluminum at annealed and normalized conditions. They found that ratcheting strain accumulation increases due to an enhancement in dislocation density with rise in the number of cycles in both conditions [30]. Creep-ratcheting is one of the most important constraints for the design and safety assessment of the components when the temperature is involved [31, 32, 33]. Creep-ratcheting tests provide significant analysis of the elastic and plastic stress states of material during cyclic loading and creep deformation $[34,35]$. 
To meet the requirements of structural applications for automotive, aircraft and defence industries, aluminum (Al) material is preferred due to its lightweight, and secure processing. Furthermore, the deployment of Al material in all fields is increasing in recent years because of its excellent mechanical properties $[36,37$, 38,39 ]. So, it is interesting to examine the mechanical behavior of nanocrystalline aluminum under high strain rate at various temperatures at nano or atomic level study. However, it is difficult to test the specimen at the nanolevel, because it is an expensive and time taking process. Molecular dynamics (MD) is one of the best tools available to model and analyse at the atomic level and thus it can be used to investigate the creep-ratcheting in nanocrystalline materials under different conditions [40, 41, 42, 43]. For instance, an MD simulation study of ultrafine-grained nanocrystalline nickel under uniaxial ratcheting has been carried out by Pal et al. [44]. They reported that both the ratcheting strain and the number of vacancies increase with the deformation temperature, whereas the dislocation density decreases [44]. Despite all the studies presented above, there is no clear or detailed assessment of the deformation behavior of nanocrystalline materials during the creep-ratcheting process.

In this paper, we have investigated the deformation behavior of nanocrystalline aluminum under the creep-ratcheting process at the atomic-level. More precisely, we examine the mechanical behavior of nanocrystalline aluminum at three temperatures $(10 \mathrm{~K}, 300 \mathrm{~K}$, and $467 \mathrm{~K})$ with a strain rate of $10^{9} \mathrm{~s}^{1}$ using MD simulations under creep-ratcheting loading for ten cycles following a uniaxial tensile loading. MD simulations provide a clear insight into the specimens in terms of their structural variation and the formation of defects during the deformation process. We examine the structural changes taking place during the deformation using different parameters: Common neighbor analysis, Centrosymmetry parameter, Dislocation analysis, and Wigner-Seitz defect analysis.

\section{Computational details}

\section{Specimen preparation}

A face-centered cubic structure of nanocrystalline aluminum specimen is created with the dimensions of $20 \mathrm{~nm} \times 20 \mathrm{~nm} \times 20 \mathrm{~nm}$ by the Voronoi method [45] using the Atomeye software [46] (Fig. 1(a)). The specimen consists of 16 uniform grains with an average grain size of $\sim 8 \mathrm{~nm}$ and contains 469064 atoms in a cubic simulation box. The orientations of $\mathrm{x}, \mathrm{y}$, and $\mathrm{z}$ axes have been taken as [100], [010], and [001]. The EAM 
(Embedded Atom Method) potential developed by Mendelev et al. [47], has been chosen to describe the interatomic interactions of $\mathrm{Al}$ atoms. The Embedded Atom Method calculates the total energy $\mathrm{E}_{\mathrm{i}}$ as per Eq. (1):

$$
E_{i}=F_{\alpha}\left(\sum_{j \neq i} \rho_{\beta}\left(r_{i j}\right)\right)+\frac{1}{2} \sum_{j \neq i} \emptyset_{\alpha \beta}\left(r_{i j}\right)
$$

Where F denotes the embedding energy and depends on $\rho$ (the atomic "electron density"); $\emptyset$ means pair potential function; $\alpha$ and $\beta$ are elemental types of atoms $i$ and $j$.
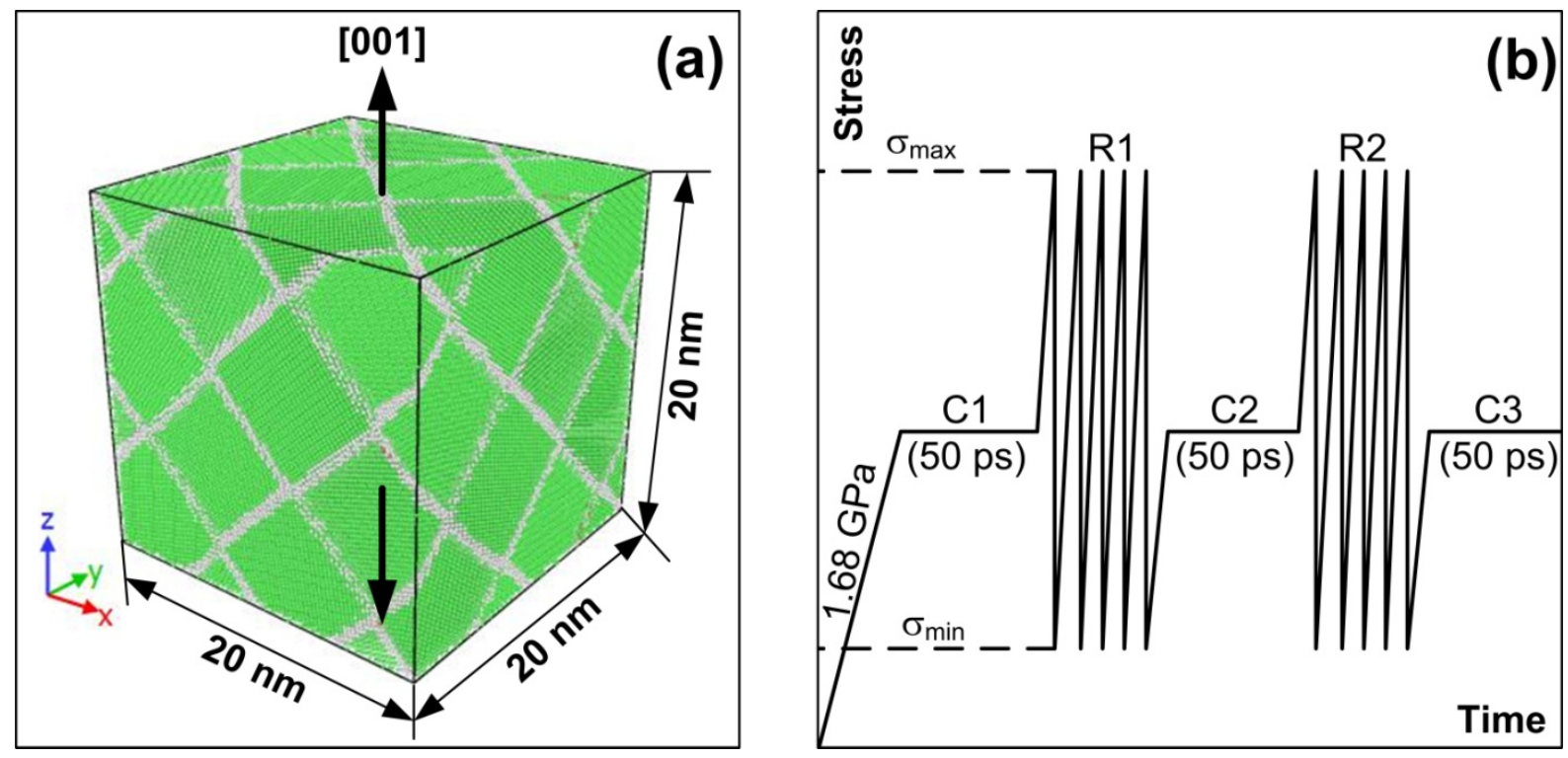

Fig. 1: Illustration of (a) Three-dimensional CNA (common neighbor analysis) snapshot of the NC Al specimen for tensile and creep-ratcheting processes. (b) Creep-ratcheting stress program. C means creep, and R means ratcheting.

Tensile test

To simulate uniaxial tensile loading, we apply periodic boundary conditions along all three directions and use a time step of 2 fs. Energy minimization is carried out to obtain minimum energy configurations using the conjugate gradient technique at $0 \mathrm{~K}$ after the specimen has been generated. Subsequently, the equilibration is performed with the NPT ensemble at $10 \mathrm{~K}, 300 \mathrm{~K}$, and $467 \mathrm{~K}\left(\sim 0.51 \mathrm{~T}_{\mathrm{m}}\right)$. Nose Hoover barostat [48], as well as Nose Hoover thermostat [49], have been used to maintain the zero pressure and regulate the temperature. After equilibration, the tensile load has been applied to the specimens in the uniaxial $\mathrm{Z}$ direction at a $10^{9} \mathrm{~s}^{-1}$ strain rate in the NVT ensemble, as shown in Fig. 1(a) [50]. 


\section{Creep-ratcheting test}

The first step of the creep ratcheting computer experiment is the tensile loading of the specimen in the $\mathrm{Z}$ direction up to $1.68 \mathrm{GPa}$ (i.e., $75 \%$ of the yield strength) at a $10^{9} \mathrm{~s}^{-1}$ strain rate. The creep deformation process is then simulated for $50 \mathrm{ps}$ at that stress using Berendsen barostat [51]. The ratcheting sequences are simulated considering two stress ratios $(\mathrm{R}=-0.4$ and -0.6$)$ for all the three different deformation temperatures (low temperature: $10 \mathrm{~K}$, room temperature: $300 \mathrm{~K}$, and high temperature: $467 \mathrm{~K}$ ). Stress ranges are chosen based on the maximum stress $\left(\sigma_{\max }\right)$, and minimum stress $\left(\sigma_{\min }\right)$ values. The maximum stress $\left(\sigma_{\max }\right)$ applied is chosen to be $90 \%$ of the ultimate tensile strength (determined by the corresponding tensile tests at the chosen temperature). Corresponding minimum stress $\left(\sigma_{\min }\right)$ values are then evaluated based on the stress ratios: $\sigma_{\min }=$ $0.4 \sigma_{\max }$ for $\mathrm{R}=-0.4 ; \sigma_{\min }=-0.6 \sigma_{\max }$ for $\mathrm{R}=-0.6$. The ratcheting deformation simulation is initiated after the simulated creep deformation process (i.e., after $50 \mathrm{ps}$ ). The applied stress is chosen to rise from the constant creep stress to the maximum stress value; then, the stress is reduced to attain the minimum stress value and subsequently increased again, repeated for a total of 5 cycles, as illustrated in Fig. 1(b). The complete simulation consists of ten alternative creep and ratcheting loading cycles.

\section{Post-processing and analysis}

All the MD (molecular dynamics) simulations are carried out with LAMMPS [52], and the visualization along with post-processing is performed with the aid of OVITO [53]. For the present work, the preferred analysis tools of OVITO are: the Centro-Symmetry Parameter (CSP) used to analyze the lattice disorder of atoms [54]; the Common Neighbor Analysis (CNA) [55, 56] used to search the local structure of atoms and twin boundaries existence in the specimen; the Wigner-Seitz defect analysis is used to identify the points defects (i.e., the vacancies) [57, 58]; the Dislocation extraction Algorithm (DXA) [59] is implemented to find the dislocations and subsequently determine their types.

\section{Results and discussion}

Pure tensile tests

The stress-strain plots of the NC Al specimens obtained for the simulated tensile test performed at the three different temperatures are illustrated in Fig. 2(a). The ultimate tensile strengths (UTS): 4.24 GPa, 3.48 $\mathrm{GPa}$, and $3.04 \mathrm{GPa}$ are attained at strains of 0.05 (for $10 \mathrm{~K}$ ), and 0.043 (for both $300 \mathrm{~K}$ and $467 \mathrm{~K}$ ). A sudden 
drop in stress is observed for low temperature, whereas the stress is found to drop steadily and gradually for the tensile deformation occurring at room and high temperatures. The maximum ultimate tensile strength is obtained at $10 \mathrm{~K}$ due to the truncated motion of dislocations as well as the low rate of dislocation generation. The dislocation density decreases just after the ultimate tensile strength as shown in Fig. 2(b). Beyond the UTS points, the dislocation density increases at $300 \mathrm{~K}$ and $467 \mathrm{~K}$ due to the rise in the dislocation generation.
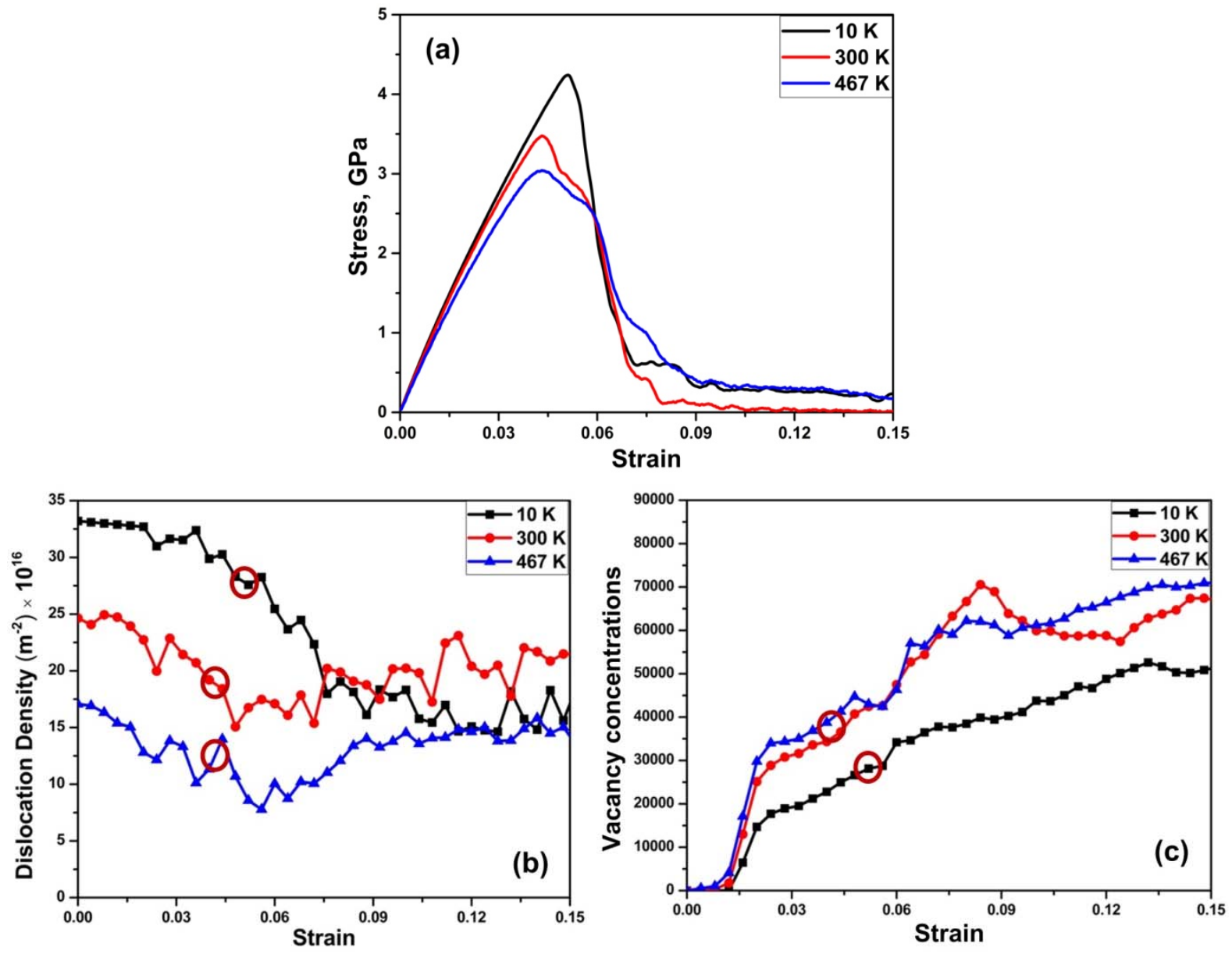

Fig. 2: (a) Stress-strain plots, (b) Dislocation density-strain plots, and (c) vacancy concentrations-strain plots during uniaxial tensile loading for $10 \mathrm{~K}, 300 \mathrm{~K}$, and $467 \mathrm{~K}$. (Brown color circles indicate the UTS points in (b and c)).

The structural variations and line defect evolution during uniaxial tensile loading are shown in Fig. $\mathbf{3 .}$ Vacancies are produced in the specimen by the motion of dislocations, and voids are generated by vacancies accumulation at the grain boundaries intersections. A similar finding has been formerly reported by Li et al. [60]. The formation of voids in the specimen leads to the initiation of the fracture process. In general, dislocation motion takes place due to the loading of the nanocrystalline specimen and triggers the formation of 
vacancies. The vacancy population is small at the initial stage of loading and increases as deformation progresses (Fig. 2(c)). The voids are found to be formed at 0.07 strain for $10 \mathrm{~K}$ temperature and 0.05 strain for both temperatures (300 K and $467 \mathrm{~K}$ ), as evident from Fig. 3(a1-c1). There is a major decline in the dislocation density during the void formation stage compared to the initial stage (Fig. 2(b)). Cracks develop in the specimen by the accumulation/connection of voids at the intergranular grain boundaries. At strains of $0.24,0.16$, and 0.14 , crack propagation has been initiated as the result of crack inceptions. Finally, the specimens fracture at 0.34 , 0.25, and 0.2 strains for $10 \mathrm{~K}, 300 \mathrm{~K}$, and $467 \mathrm{~K}$, respectively, as seen in Fig. 3(a3-c3) and (a4-c4). An increase in the deformation temperature (from $10 \mathrm{~K}$ to $467 \mathrm{~K}$ ) leads to a decrease in the strain required to reach the different stages (i.e., void formation, crack inception, crack propagation, and fracture) of the deformation process as shown in Fig. 3. The fracture in the specimen takes place along the grain boundaries, leading to intergranular fracture (Fig. 3(a4-c4)). 


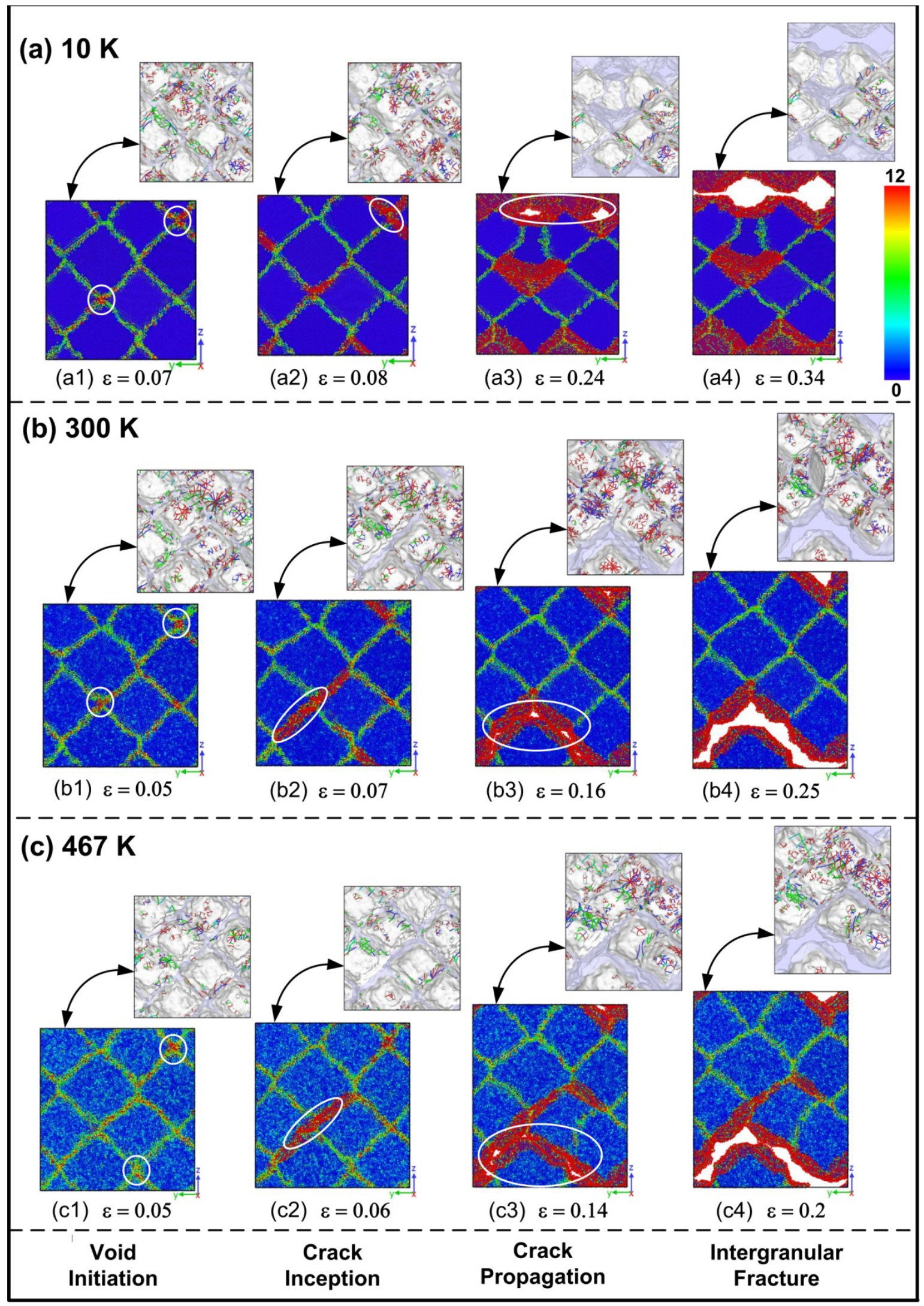

Fig. 3: Atomic snapshots illustrating the deformation behavior of the $\mathrm{NC}$ Al specimen during uniaxial tensile loading at various strains for three different temperatures: (a) low temperature $(10 \mathrm{~K})$, (b) room temperature $(300 \mathrm{~K})$, and (c) high temperature $(467 \mathrm{~K})$. 
Creep ratcheting tests

The low-temperature case: $10 \mathrm{~K}$

The strain vs. time and stress vs. strain curves for the stress ratios $(\mathrm{R}=-0.4$ and $\mathrm{R}=-0.6)$ are implemented for ratcheting deformation during the creep-ratcheting theoretical experiment performed at $10 \mathrm{~K}$, as shown in Fig. 4(a1-a2) and (b1-b2). The strain-time plots exhibit an almost linear strain, and only a very slight increase in the strain is observed at this temperature, as seen in the insets of Fig. 4(a1) and (b1) in the creep regions. The evaluated accumulated strain is smaller for the ratcheting stress ratio $\mathrm{R}=-0.6$ compared to the ratcheting stress ratio $\mathrm{R}=-0.4$, as seen in Fig. 4(a1) and (b1). Insets of Fig. 4(a2) and Fig. 4(b2) shows the portion of plastic deformation, where the hysteresis loops are thin.

(a) $\mathrm{R}=-0.4 ; 10 \mathrm{~K}$

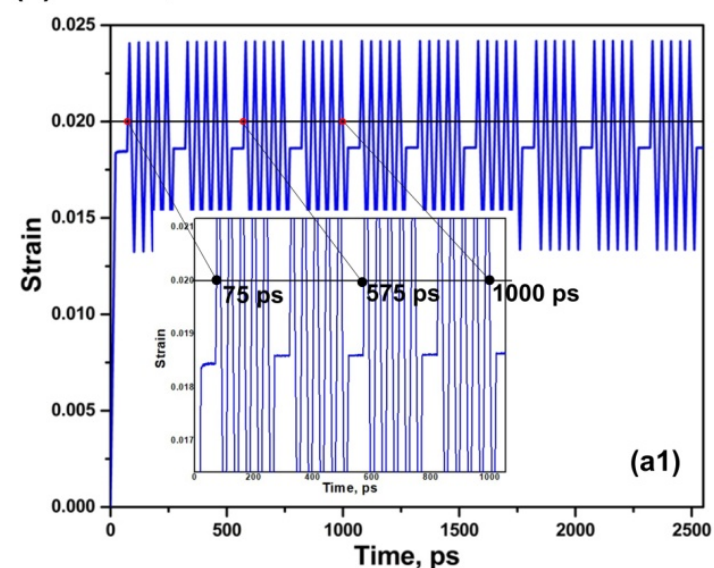

(b) $\mathrm{R}=-0.6 ; 10 \mathrm{~K}$

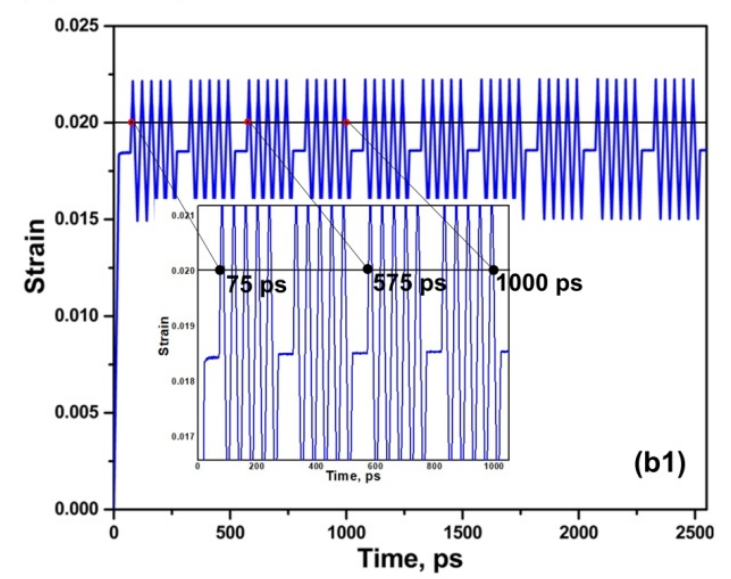

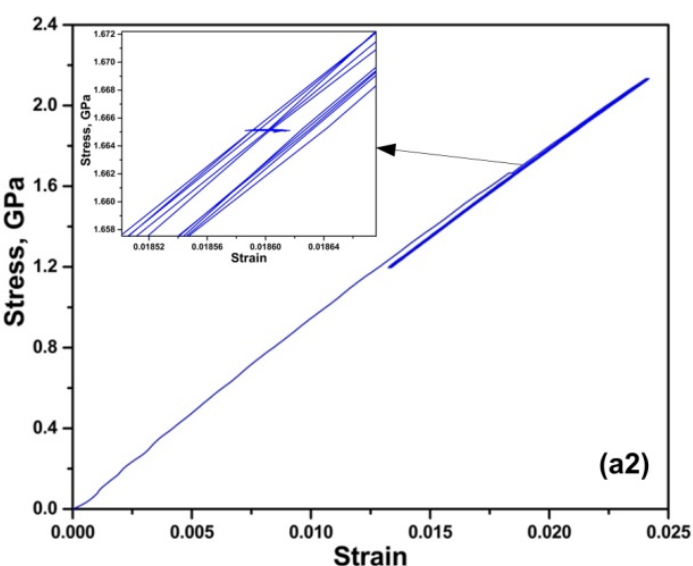

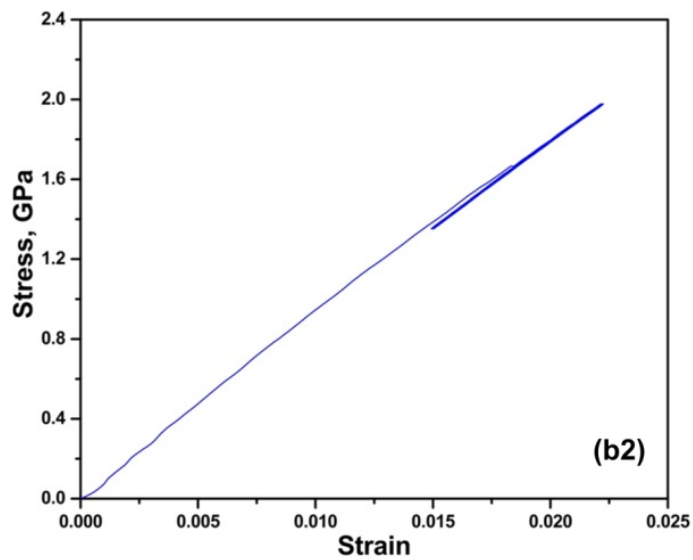

Fig. 4: Strain vs. time and stress vs. strain plots of the NC Al specimen during the creep-ratcheting deformation for the ratcheting stress ratios of (a) $R=-0.4$ and (b) $R=-0.6$ at $10 \mathrm{~K}$. (Insets in Fig. of (a1) and (b1) show zooms on three-time steps. 
Fig. 5 illustrates the evolution of dislocation density, vacancy concentrations, as well as the evolution of each kind of dislocations at $10 \mathrm{~K}$. Fig. 5(a) shows that the total dislocation density is lower at the final stages of the simulations than at the initial stages because the dislocation annihilation rate is higher than the dislocations generation rate. Fig. 5(b) shows that the population of vacancies fluctuates: the vacancy concentrations decreases during creep and rises and falls (increases and decreases) during ratcheting: it follows the creep and ratcheting stages. Overall, the vacancy concentrations increase slightly from beginning to the end of the simulation, as shown in Fig. 5(b). The dislocations existing in the nanocrystalline specimen are of two types: perfect dislocations and partial dislocations: Shockley, Frank, Hirth, and Stair-rod dislocations. Shockley dislocations are known as glissile (mobile) dislocations, whereas the Stair-rod, Hirth, and Frank dislocations are known as sessile (immobile) dislocations. Our results indicate that the majority of the dislocations present and created in the material are perfect dislocations and Shockley dislocations. Their densities decrease first and increase later during the initial stages of loading then fluctuate up to the last stage of loading. The fluctuation of the densities of Frank and stair-rod dislocations is less pronounced, and the amount of stair-rod dislocations is minimal. The stress ratio seems to hardly affect the dislocation density evolution, i.e., both stress ratios display a similar range of dislocation densities, as seen in Fig. 5(c-d). For both ratios, the perfect and Shockley partial dislocations appear to facilitate the deformation process. 

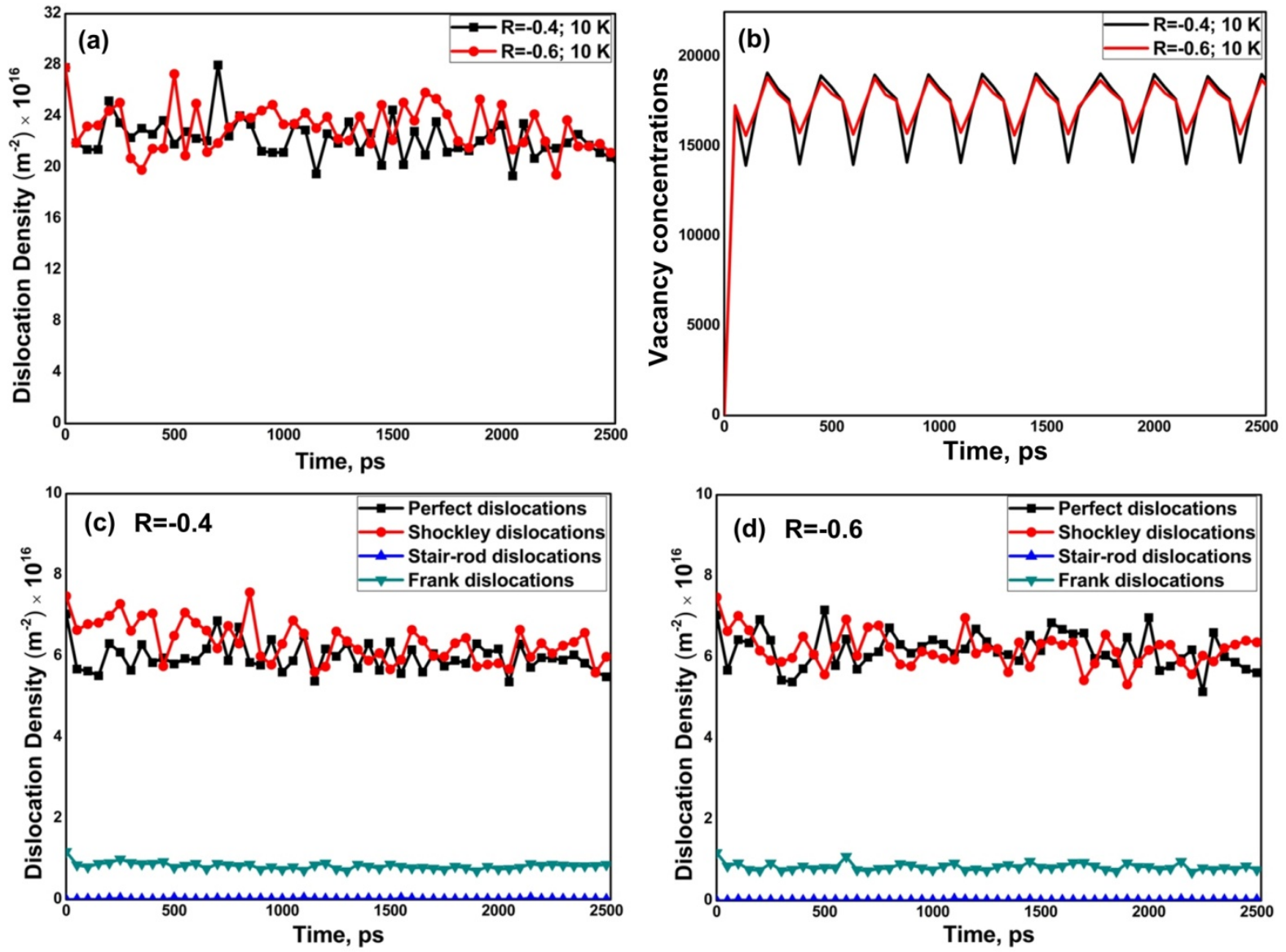

Fig. 5: (a) Overall dislocation density-time plots, (b) vacancy concentrations-time plots, and (c-d) Dislocation density of different types of dislocations-time plots for the two ratcheting stress ratios at $10 \mathrm{~K}$.

Fig. 6 shows the structural evolution during the creep-ratcheting loading conditions at $10 \mathrm{~K}$. Fig. 6(a) represents the specimen before the creep ratcheting loading. At this stage, the dislocations are quite numerous (i.e., Shockley partial dislocations and perfect dislocations), and clearly shown in Fig. 6(a3). After ten cycles of creep-ratcheting loading, the dislocation density has decreased in the specimen (Fig. 6(b3-c3)), and the grain boundaries have thickened in the specimen. All these data are typical of cyclic hardening, where the strain accumulation rate is low due to an increase in resistance for deformation, which causes small deformation to the specimen (i.e., grain boundary thickening and sliding only) and leads to a high dislocation density. 


\section{(a) Specimen before loading; $10 \mathrm{~K}$}
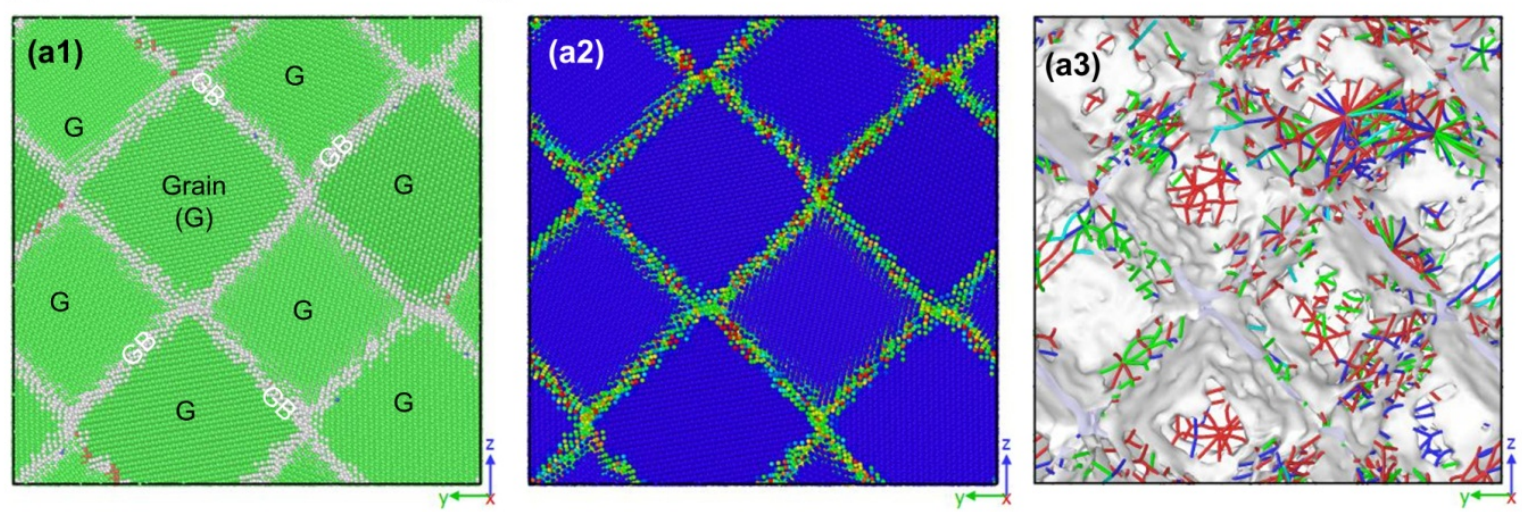

\section{(b) Specimen after loading; $R=-0.4 ; 10 \mathrm{~K}$}
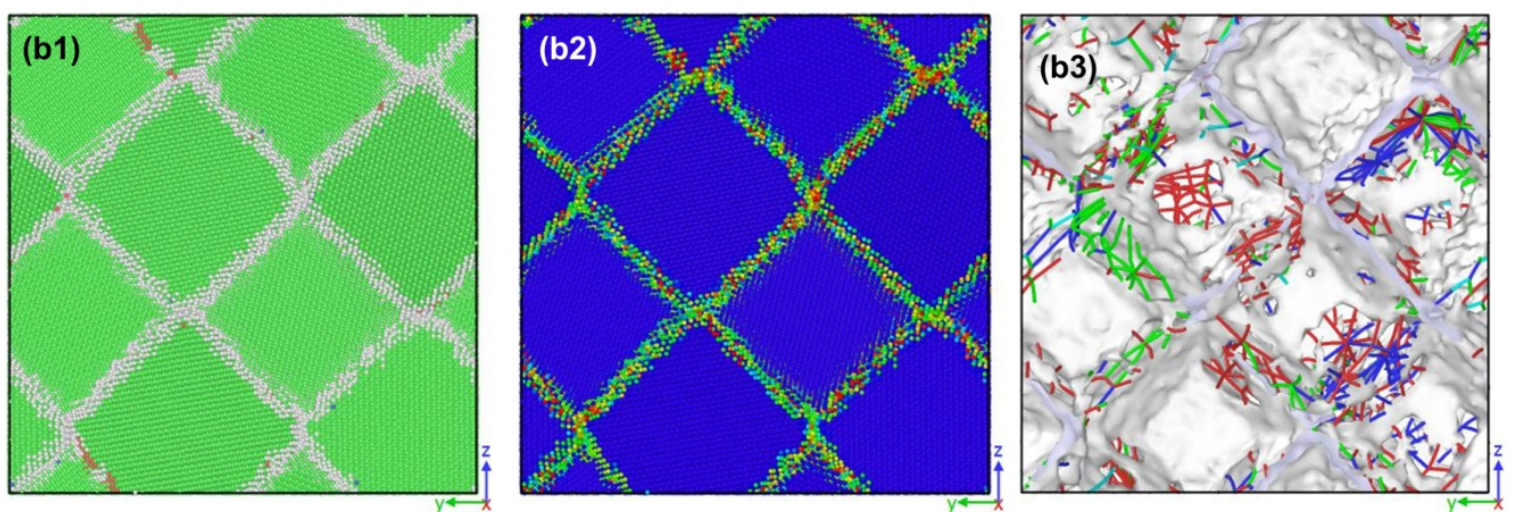

(c) Specimen after loading; $R=-0.6 ; 10 \mathrm{~K}$
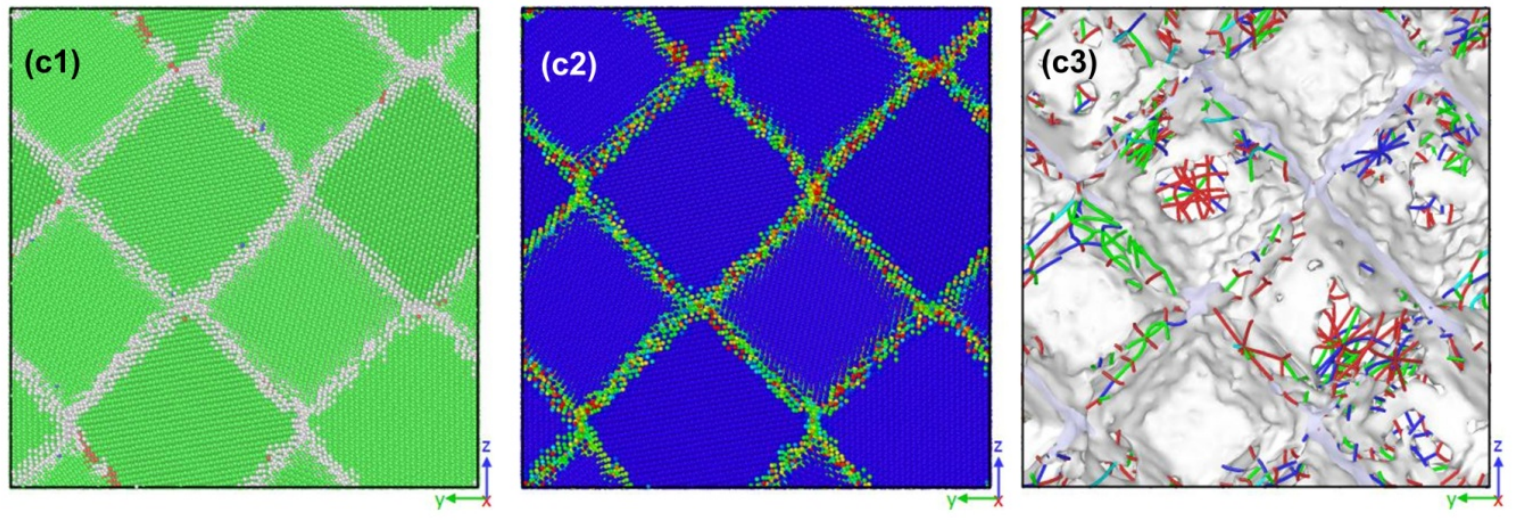

Fig. 6: Atomic snapshots of the NC Al specimen with CNA, CSP, and DXA illustrating the creep-ratcheting deformation behavior at $10 \mathrm{~K}$, (a) specimen before loading, and (b-c) specimens subjected to two ratcheting stress ratios after loading.

The room temperature case: $300 \mathrm{~K}$

Fig. 7 shows the strain-time and stress-strain plots at room temperature. Fig. 7(a1) and (b1) illustrates the gradual rise in strain during the creep-ratcheting deformation process. At this temperature, two 
regimes/stages can be identified: the first one that starts during the preliminary stage of loadings and lasts up to $522 \mathrm{ps}$ is characterized by low accumulation of plastic strain; the second one is described by a steady and more pronounced increase of the strain. The first stage corresponds to cyclic hardening: the resistance to deformation is high, and strain accumulation is low during the creep-ratcheting deformation. During the second stage, the deformation is moderate, and the strain accumulation is steady and dominated by cyclic hardening. An increase of the strain vs. time at this temperature compared to that for $10 \mathrm{~K}$ temperature can be accounted for by the fact that dislocation generation is more pronounced at room temperature than at $10 \mathrm{~K}$, as shown in Fig. 8, which represents the overall evolution of the dislocation density, vacancy population, and the different types of dislocations.

(a) $R=-0.4 ; 300 \mathrm{~K}$

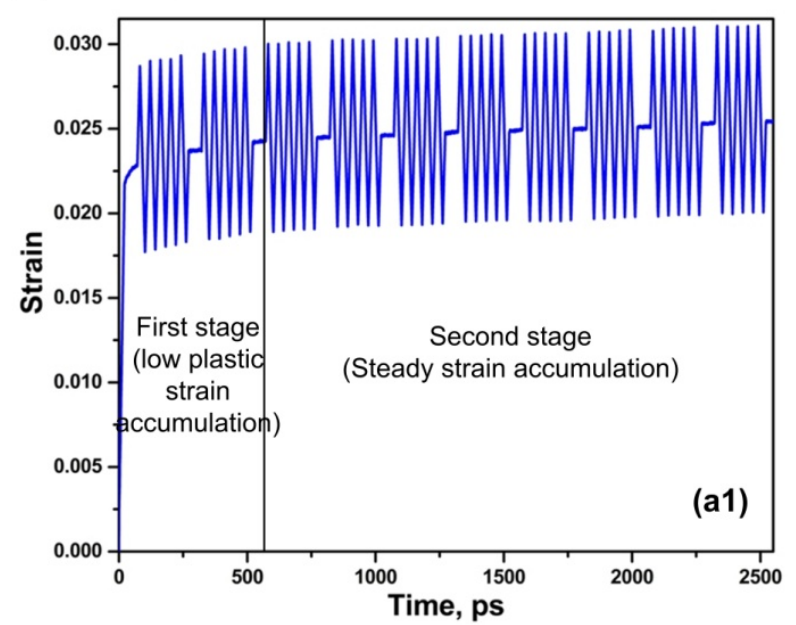

(b) $R=-0.6 ; 300 \mathrm{~K}$

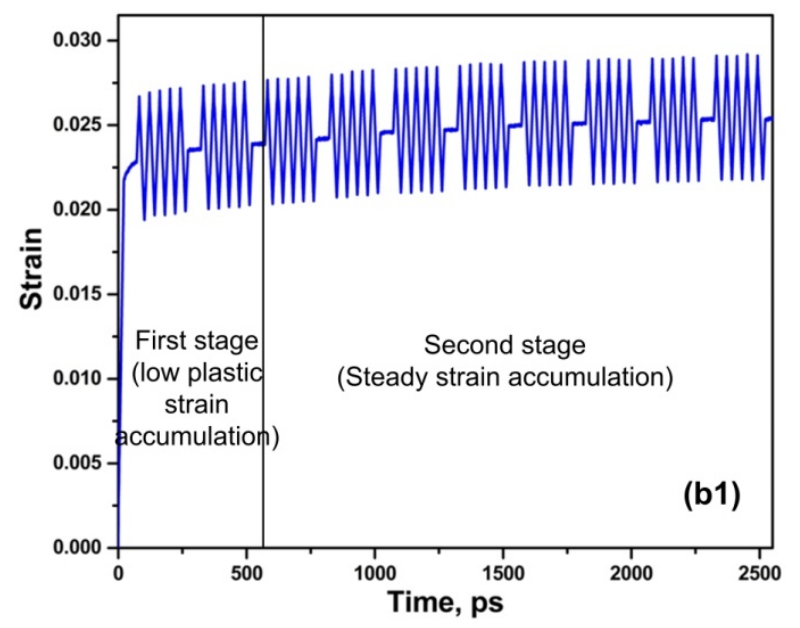

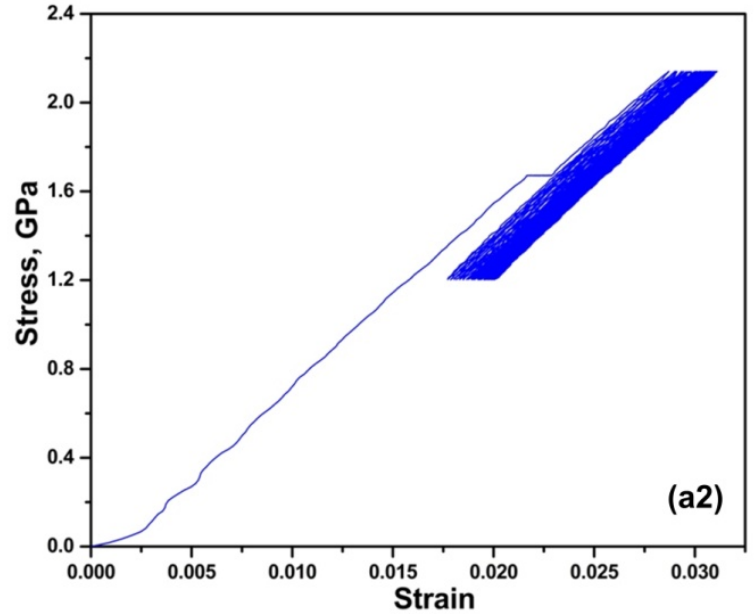

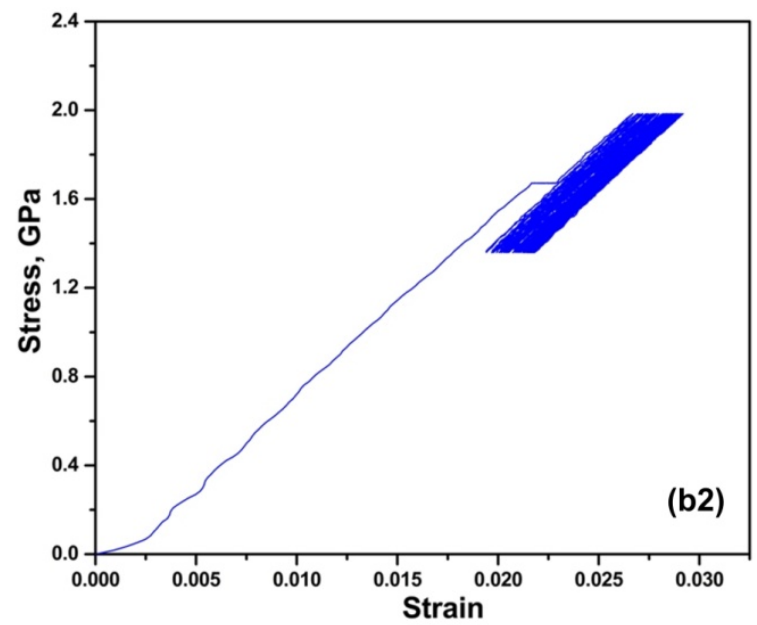

Fig. 7: Strain-time and stress-strain plots of the $\mathrm{NC} \mathrm{Al} \mathrm{specimen} \mathrm{during} \mathrm{the} \mathrm{creep-ratcheting} \mathrm{deformation} \mathrm{for} \mathrm{the}$ ratcheting stress ratios (a) $R=-0.4$ and (b) $R=-0.6$ at $300 \mathrm{~K}$. 
At room temperature, an increase in dislocation generation and dislocation motion leads to a rise in the dislocation density, as shown in Fig. 8(a). The vacancy population is also higher than at $10 \mathrm{~K}$ (Fig. 8(b)). Still, it follows the same pattern: the vacancy concentrations decreases during creep and rises and falls (increases and decreases) during ratcheting. Similar to what is observed at $10 \mathrm{~K}$, the density of Shockley partial and perfect dislocations is higher than the density of Frank and stair rods dislocations (Fig. 8(c-d)).
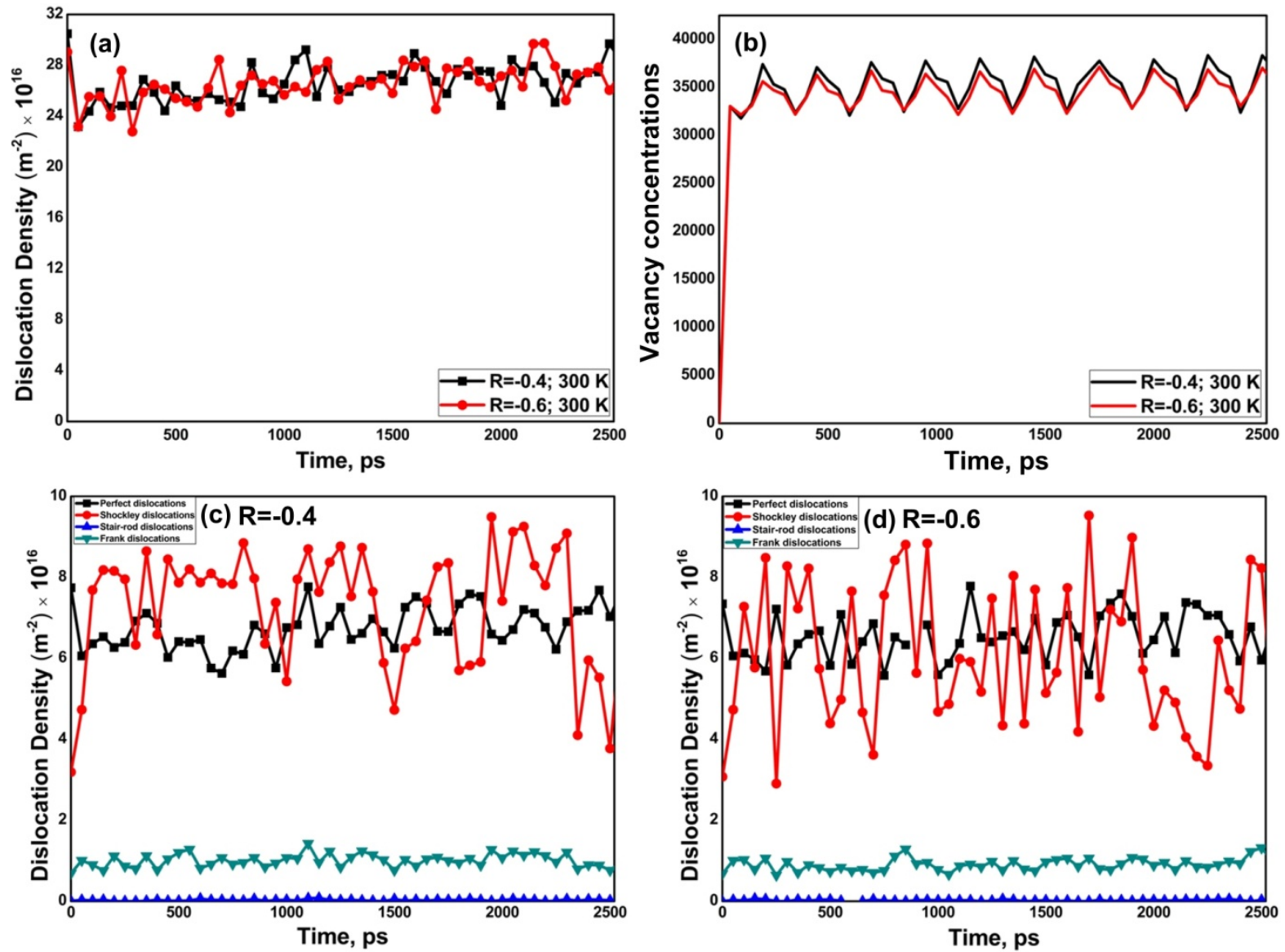

Fig. 8: (a) Overall dislocation density-time plots, (b) vacancy concentrations-time plots, and (c-d) Dislocation density of different types of dislocations vs. time plots at $300 \mathrm{~K}$.

Fig. 9 illustrates the structural variation and defect evolution under creep-ratcheting loading conditions for room temperature. During the simulation, the dislocation entanglements have increased, and multiple dislocations have been generated due to a rise in the rate of dislocation generation and dislocation movement. Grain boundary thickening, grain boundary sliding, and twin boundaries have been identified in the specimen after completion of the simulation (Fig. 9(b1-c1)). The atomic strain snapshot in the inset shows that the deformation is carried out along the grain boundaries. It indicates the existence of grain boundary diffusion in the nanocrystalline structure, as seen in Fig. 9(b1-c1). Furthermore, the accumulation of atoms at the grain 
boundaries leads to grain boundary thickening in the specimen, as seen in Fig. 9(b1-b2 and c1-c2). Grain boundary motion has been accelerated with the temperature increase, leading to the deformation of the specimen through grain boundary diffusion.

\section{(a) Specimen before loading; $300 \mathrm{~K}$}
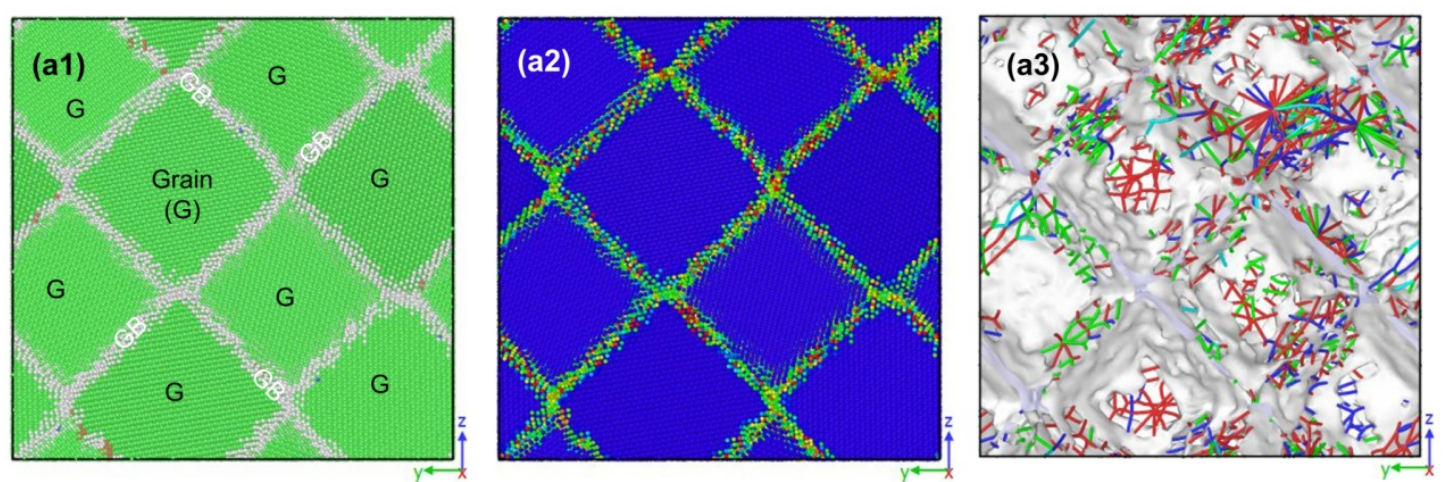

(b) Specimen after loading; $R=-0.4 ; 300 \mathrm{~K}$
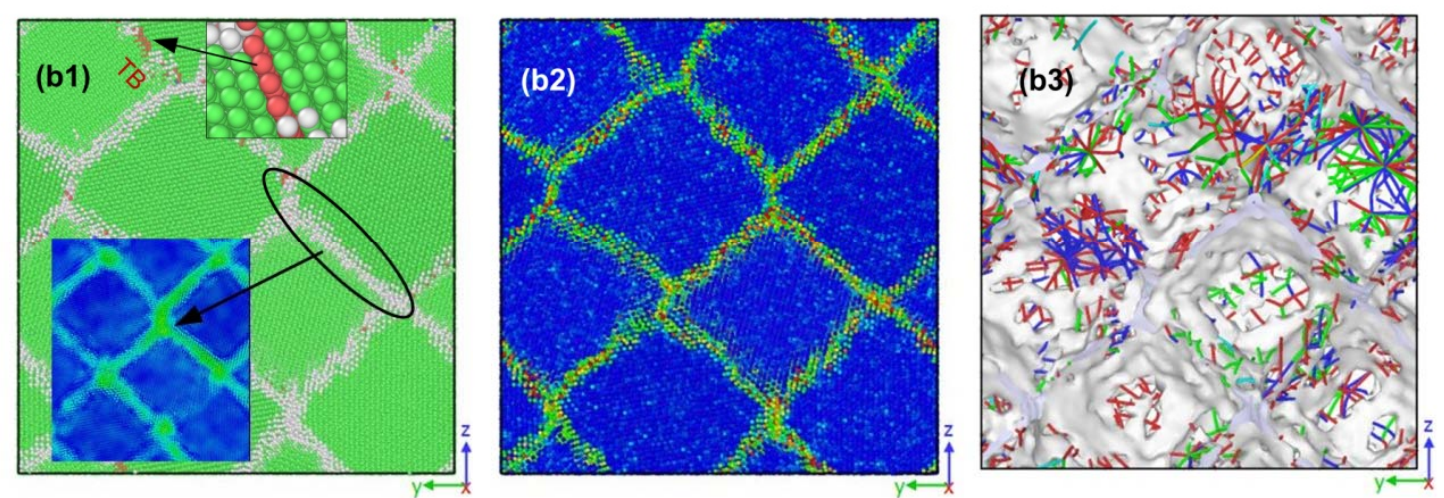

(c) Specimen after loading; $R=-0.6 ; 300 \mathrm{~K}$
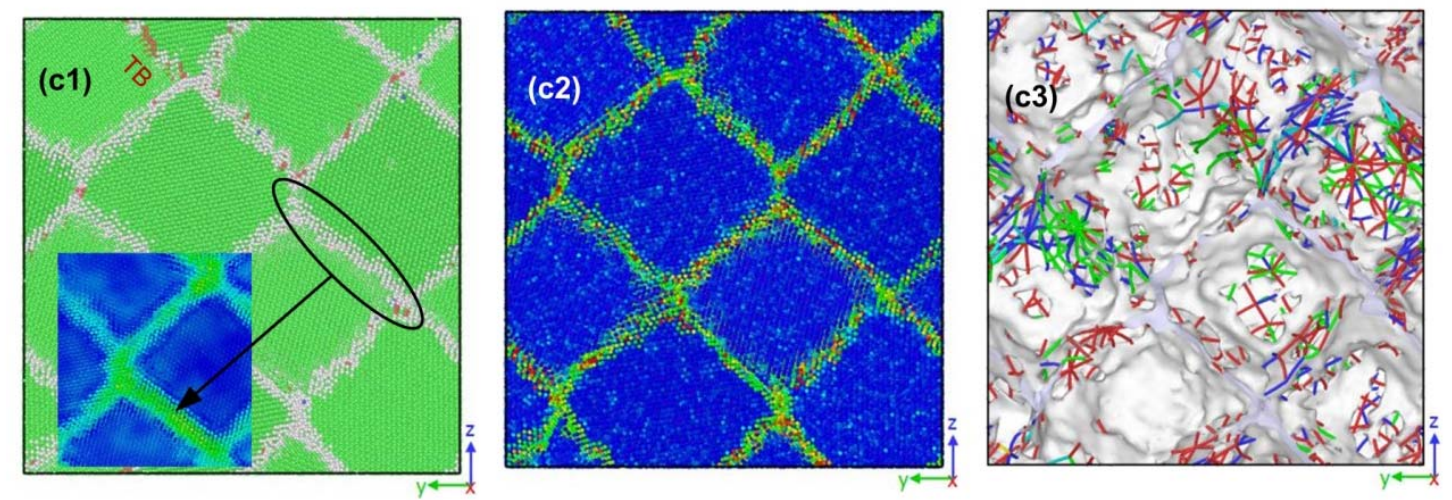

Fig. 9: Atomic snapshots of the NC Al specimen with CNA, CSP, and DXA illustrating the creep-ratcheting deformation behavior at $300 \mathrm{~K}$, (a) specimen before loading, and (b-c) specimens after loading. Insets (b1) and (c1) show the grain boundary deformation using atomic strain snapshot and twin boundary using CNA snapshot subjected to the two ratcheting stress ratios. 
Fig. 10(a1) and (b1) represent the strain versus time and the stress versus strain curves obtained at 467 K. At this temperature, three different stages are observed: cyclic hardening up to $522 \mathrm{ps,} \mathrm{characterized} \mathrm{by} \mathrm{the}$ low accumulation of plastic strain; An intermediate stage: where the increase of strain is steady and more pronounced, up to $1772 \mathrm{ps;}$ and a final stage where the strain accumulation is high due to a decrease in the resistance to deformation that lasts until the end of the simulation $(2522 \mathrm{ps})$. These three stages have been reported for the SA333 C-Mn steel in literature [61]. The strain vs. time plots have shifted towards higher values of strain compared with the other temperatures, and the maximum accumulated plastic strain is obtained for the stress ratio of $\mathrm{R}=-0.4$. Fig. 10(a2) and (b2) shows the stress-strain hysteresis loops of a plastic region in steady propagation mode: the hysteresis loops spread in a vast zone with strain and the strain accumulation area increases regarding the number of cycles.

(a) $\mathrm{R}=-0.4 ; 467 \mathrm{~K}$

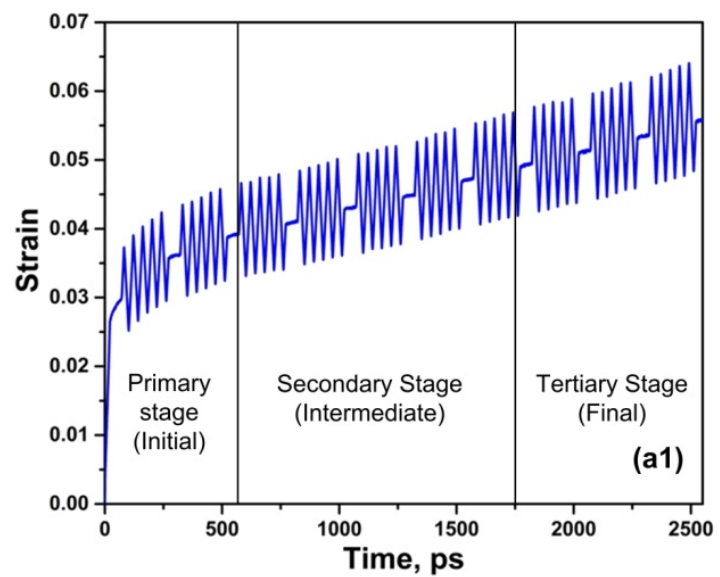

(b) $R=-0.6 ; 467 \mathrm{~K}$

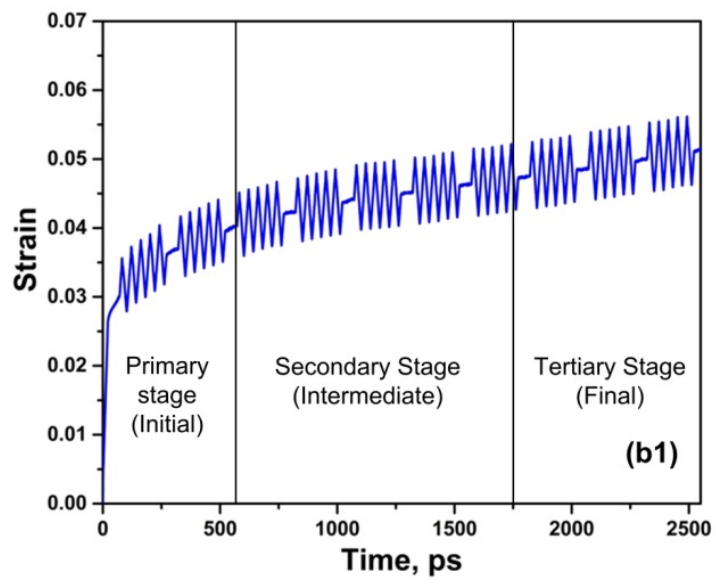

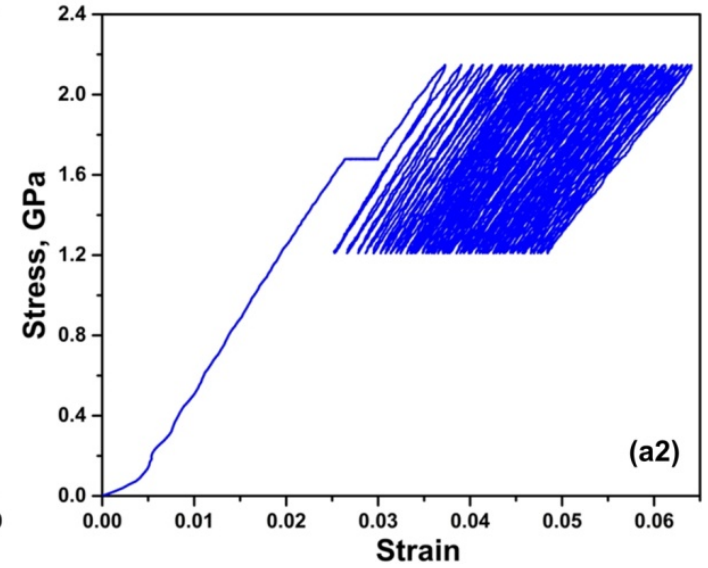

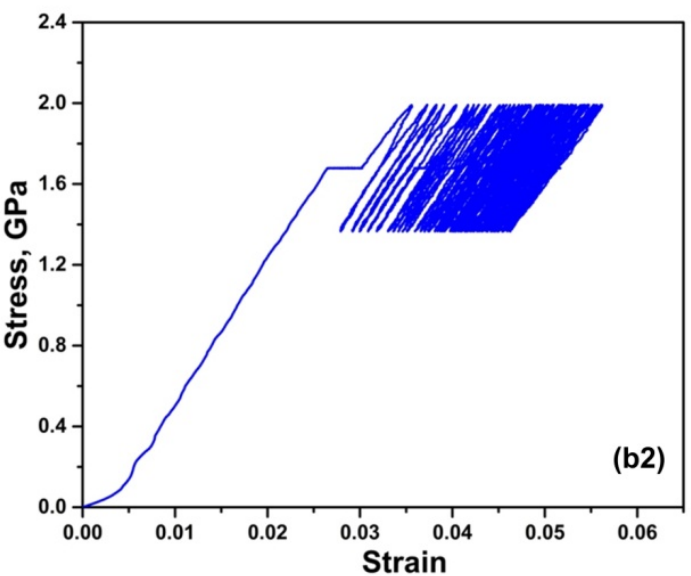

Fig. 10: Strain vs. time and stress vs. strain of the $\mathrm{NC} \mathrm{Al} \mathrm{specimen} \mathrm{during} \mathrm{the} \mathrm{creep-ratcheting} \mathrm{deformation} \mathrm{for}$ the ratcheting stress ratios of (a) $\mathrm{R}=-0.4$ and (b) $\mathrm{R}=-0.6$ at $467 \mathrm{~K}$. 
At $467 \mathrm{~K}$, the overall dislocation density is low compared to the densities $10 \mathrm{~K}$ and $300 \mathrm{~K}$ (Fig. 11(a)), because the dislocation annihilation rate is more than the dislocation generation rate at high temperature. It is in agreement with the literature findings [62]. The corresponding dislocation density vs. strain plots is shown in Fig. S1. Regarding the population of vacancies, Fig. 11(b) shows that the vacancy concentrations is higher at high temperatures, and the deviations much less pronounced than at $10 \mathrm{~K}$ and $300 \mathrm{~K}$ owing to higher diffusion rate as well rapid dislocation motion and generation. Fig. 11(c-d) represents the evolution of the dislocation densities at $467 \mathrm{~K}$. It is observed that a rise in temperature causes a decrease in the quantity of Shockley partial, perfect, and other dislocations (Fig. 11(c-d)). The Shockley partial and perfect dislocations still have a leading role in the creep-ratcheting deformation process at this temperature.
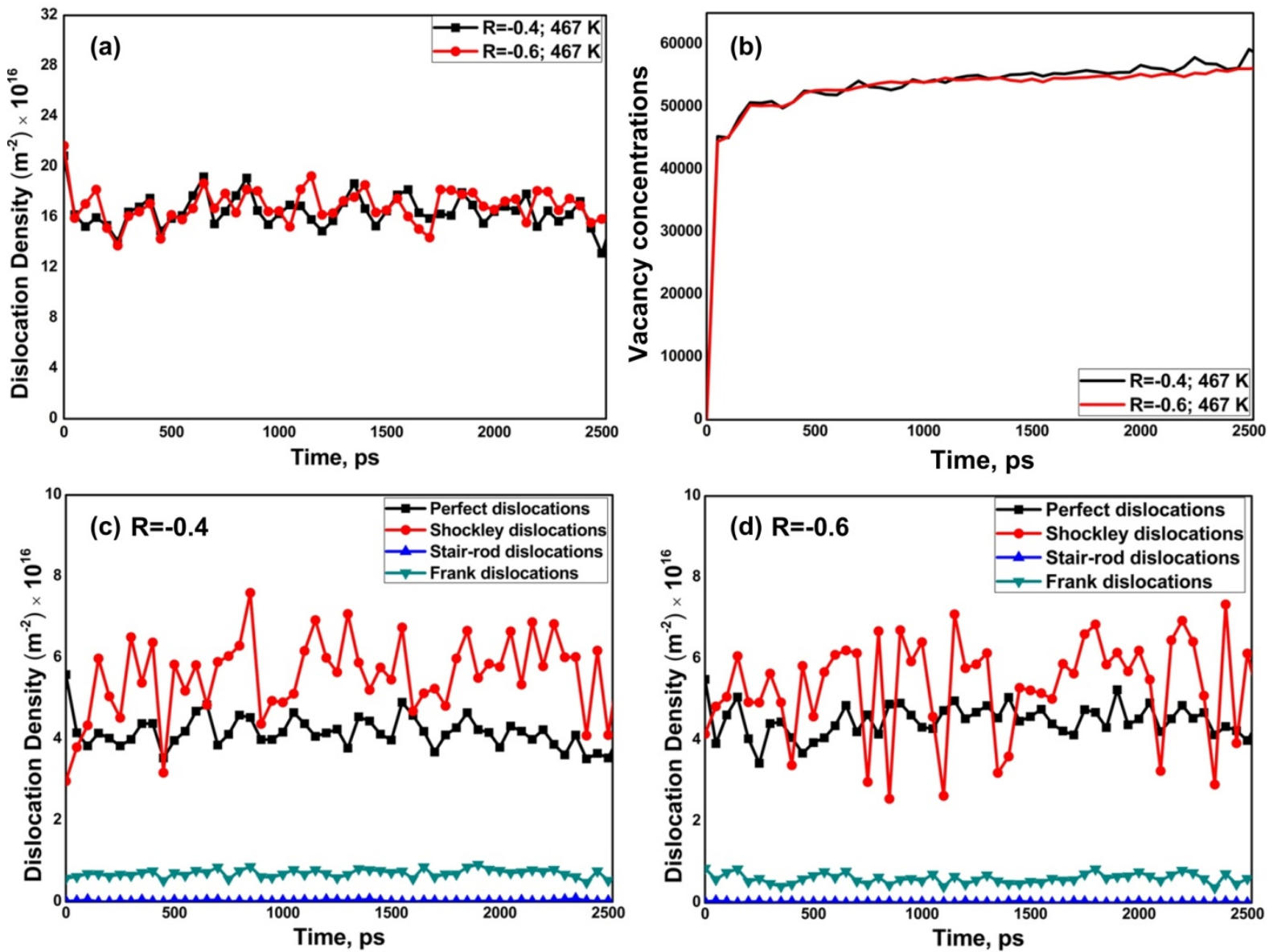

Fig. 11: (a) Overall dislocation density vs. time plots, (b) vacancy concentrations vs. time plots, and (c-d) Dislocation density of different types of dislocations vs. time plots at $467 \mathrm{~K}$. 
Fig. 12 illustrates the structural evolution of the $\mathrm{NC} \mathrm{Al}$ at $467 \mathrm{~K}$. The dislocation quantity has decreased in the specimen after the completion of ten creep-ratcheting deformation cycles (Fig. 12(b3-c3)) in contrast to before the loading stage (Fig. 12(a3)). At $467 \mathrm{~K}$ temperature, higher deformation takes place in the specimen through grain boundary motion, sliding, and grain boundary thickening. Void initiation (highlighted with a white circle) is observed in the specimen as well as grain boundary broadening. Twin boundaries are also noticed (Fig. 12(b1-c1) and (b2-c2)).

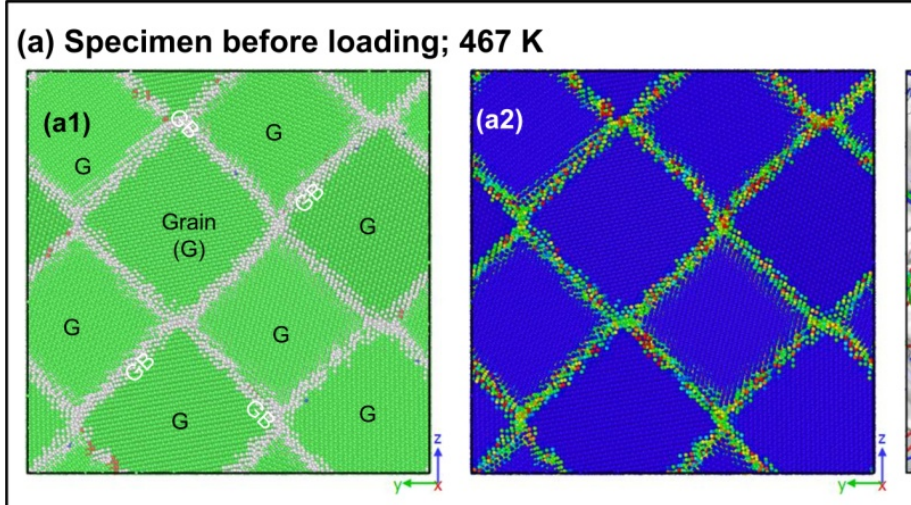

(b) Specimen after loading; $R=-0.4 ; 467 \mathrm{~K}$
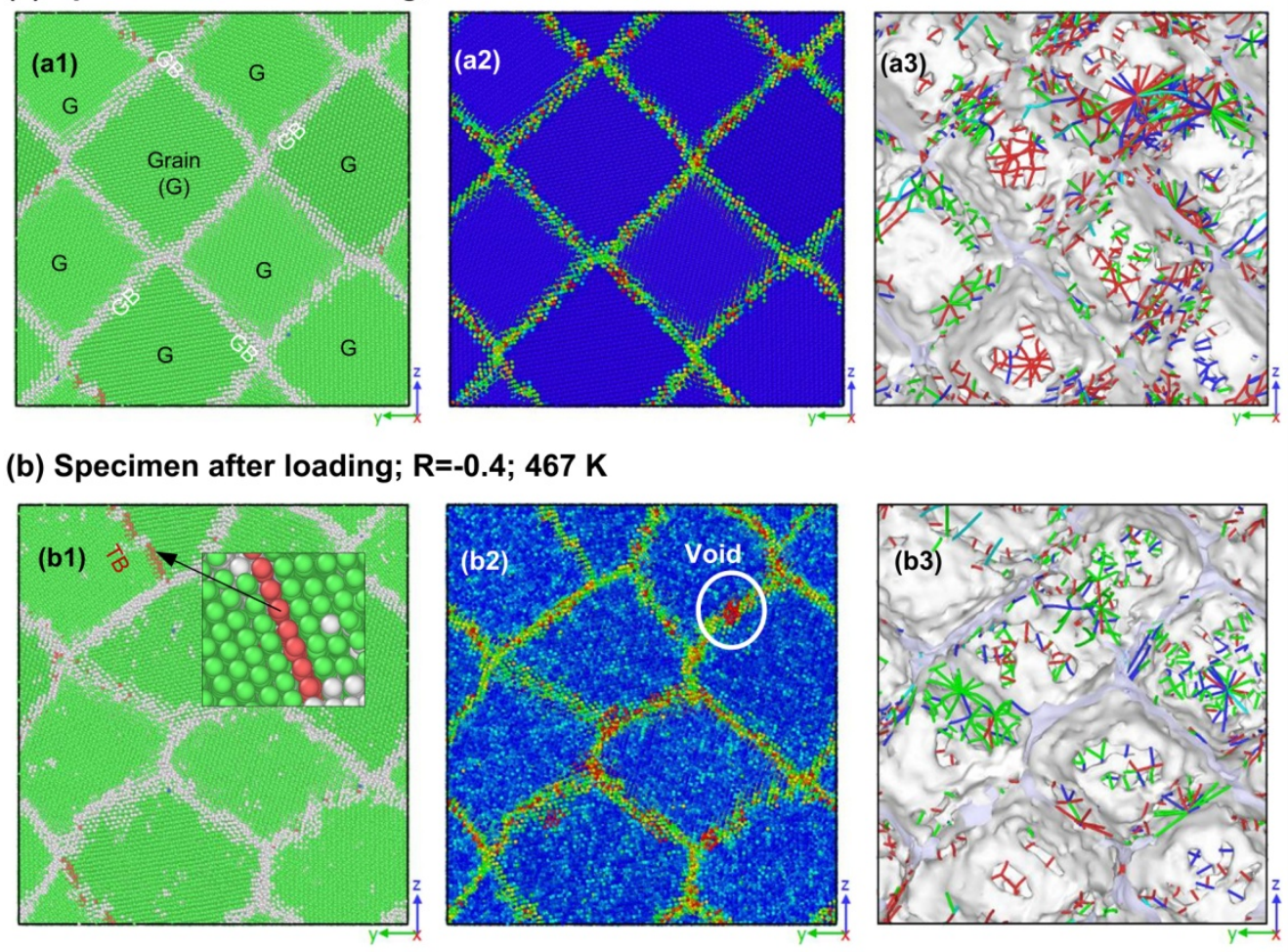

(c) Specimen after loading; $R=-0.6 ; 467 \mathrm{~K}$

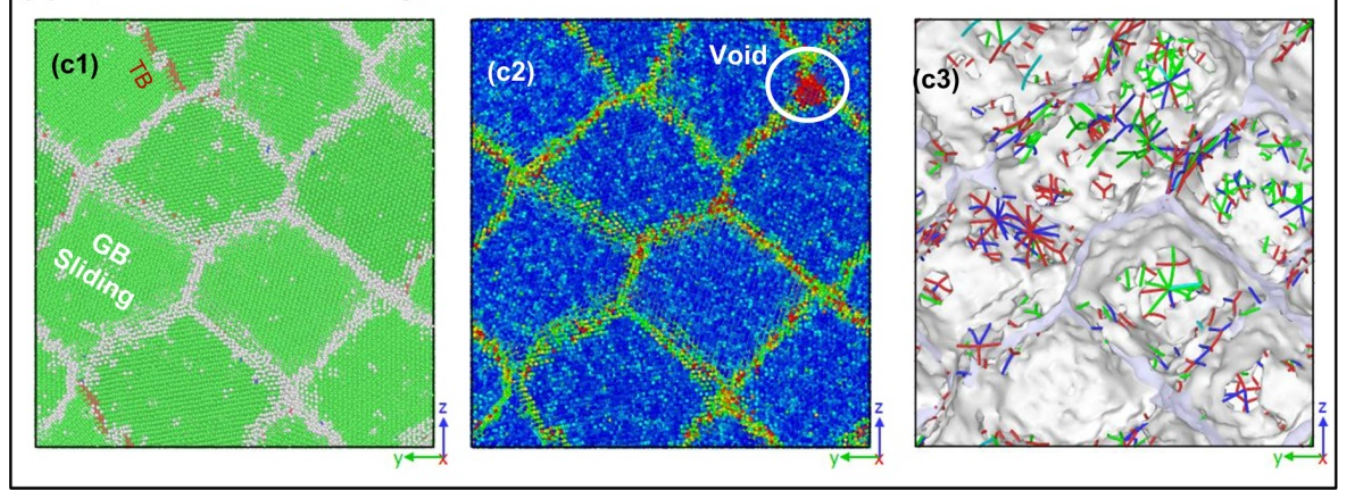

Fig. 12: Atomic snapshots of the NC Al specimen with CNA, CSP, and DXA illustrate the creep-ratcheting deformation behavior at $467 \mathrm{~K}$, (a) specimen before loading and (b-c) specimens after loading subjected to two stress ratios of ratcheting. Inset CNA snapshot of (b1) shows the zoom mode of twin boundary. 
Table 1 contains a summary of the behaviors observed for the three temperatures during the creepratcheting deformation process. At $10 \mathrm{~K}$ temperature, there is grain boundary thickening. On the other hand, at $300 \mathrm{~K}$ temperature, grain boundary thickening, sliding, and twin boundaries based mechanisms are operative. At $467 \mathrm{~K}$ temperature, the microstructures show void initiation, grain boundary thickening, sliding, and twin boundaries.

Both Fig. 13 and Table 2 summarize the operative mechanism correlating along with strain evolution. At $10 \mathrm{~K}$, minimal strain accumulation is observed during the simulations. At $300 \mathrm{~K}$, the strain accumulation is higher than at $10 \mathrm{~K}$. At $467 \mathrm{~K}$, three stages are visible: cyclic hardening during the initial phase, a balance between cyclic hardening and cyclic softening during the intermediate stage, and cyclic softening during the final stages. The end of the primary stage arrives close to $522 \mathrm{ps,} \mathrm{the} \mathrm{secondary/intermediate} \mathrm{stage} \mathrm{lasts} \mathrm{from}$ 522 ps to 1772 ps and tertiary stage from 1772 ps to the end of the simulation, i.e., 2522 ps.

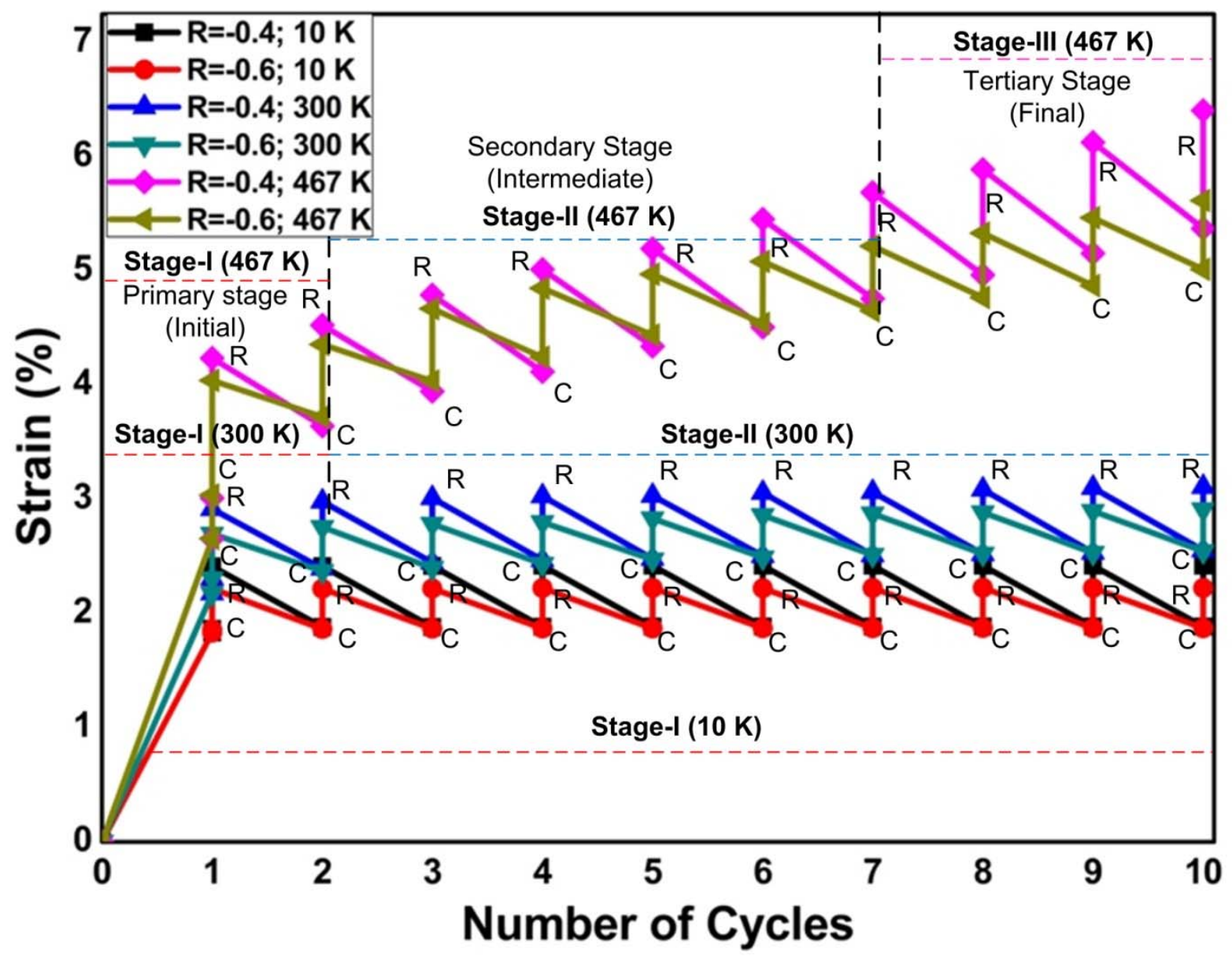

Fig. 13: Strain vs. the number of cycles for the two stress ratios of ratcheting during creep-ratcheting deformation for three different temperatures ( $\mathrm{C}$ means creep and $\mathrm{R}$ denote ratcheting). 
Dislocations motion causes materials to deform plastically. During creep-ratcheting deformation, dislocations have generated and annihilated. The overall dislocation density is the highest at room temperature. Shockley partial dislocations have formed because of the high strain rate, nanocrystalline structure, glissile (mobile) nature, and supportive for dislocation movement and whereas other partial dislocations have sessile nature and also provide an obstruction to dislocations motion during the deformation. The density of Shockley partial and perfect dislocations is always much larger than the density of Frank and stair rod partial dislocations, whatever the deformation temperature and the stress ratio. The Shockley partial and perfect dislocations are thus predominantly engaged for the driving of the creep-ratcheting deformation process. Our simulations also show that at higher temperatures, dislocation annihilation is even higher. It leads to a decrease in the overall dislocation density. The stress ratio does not seem to impact the dislocation density much.

Table 1: Summary of the findings involved in the creep-ratcheting deformation process.

\begin{tabular}{|c|c|c|c|c|}
\hline Temperature & Microstructure evolution & Stages & Dislocation density & $\begin{array}{c}\text { Vacancy } \\
\text { concentrations }\end{array}$ \\
\hline $10 \mathrm{~K}$ & Grain boundary thickening & $\begin{array}{l}\text { Cyclic hardening observes } \\
\text { throughout the whole } \\
\text { simulation }(0-2522 \mathrm{ps}) \text {. }\end{array}$ & $\begin{array}{l}\text { For both stress ratios, the } \\
\text { overall dislocation } \\
\text { density is high at the } \\
\text { starting point and low at } \\
\text { the end. } \\
\text { The overall dislocation } \\
\text { density }\left(\sim 28 \mathrm{~m}^{-2}\right) \text { is } \\
\text { moderate. }\end{array}$ & $\begin{array}{l}\text { The vacancy } \\
\text { population } \\
\text { fluctuates, and the } \\
\text { overall population } \\
\text { of vacancy is low. }\end{array}$ \\
\hline $300 \mathrm{~K}$ & $\begin{array}{l}\text { Grain boundary thickening } \\
\text { Grain boundary sliding } \\
\text { Twin boundaries }\end{array}$ & $\begin{array}{l}\text { Cyclic hardening notices up to } \\
522 \text { ps, and consistent } \\
\text { enrichment of accumulation of } \\
\text { plastic strain observes from } \\
522 \text { to } 2522 \text { ps. }\end{array}$ & $\begin{array}{l}\text { For both stress ratios, the } \\
\text { overall dislocation } \\
\text { density is an increasing } \\
\text { manner subjected to } \\
\text { time. } \\
\text { The overall dislocation } \\
\text { density }\left(\sim 31 \mathrm{~m}^{-2}\right) \text { is high. }\end{array}$ & $\begin{array}{l}\text { The vacancy } \\
\text { population } \\
\text { fluctuates, and the } \\
\text { overall population } \\
\text { of vacancies is } \\
\text { moderate. }\end{array}$ \\
\hline $467 \mathrm{~K}$ & $\begin{array}{l}\text { Void initiation } \\
\text { Grain boundary thickening } \\
\text { Grain boundary sliding } \\
\text { Twin boundaries }\end{array}$ & $\begin{array}{l}\text { Cyclic hardening observes up } \\
\text { to } 522 \text { ps; the balance between } \\
\text { cyclic hardening and cyclic } \\
\text { softening from } 522 \text { to } 1772 \mathrm{ps} \text {; } \\
\text { cyclic softening from } 1772 \text { to } \\
2522 \mathrm{ps} \text {. }\end{array}$ & $\begin{array}{l}\text { For both stress ratios, the } \\
\text { overall dislocation } \\
\text { density decreases with } \\
\text { time. } \\
\text { The overall dislocation } \\
\text { density }\left(\sim 22 \mathrm{~m}^{-2}\right) \text { is low. }\end{array}$ & $\begin{array}{l}\text { The vacancy } \\
\text { population } \\
\text { fluctuates much } \\
\text { less than at lower } \\
\text { temperatures, and } \\
\text { the overall } \\
\text { population of } \\
\text { vacancy is high. }\end{array}$ \\
\hline
\end{tabular}

Regarding vacancies, our study shows that, as the deformation progresses, the vacancy population increases and decreases during ratcheting. The fluctuations are very pronounced at $10 \mathrm{~K}$ and $300 \mathrm{~K}$ and less 
visible at $467 \mathrm{~K}$. The variations in the vacancy population are higher at low and room deformation temperatures during the creep and ratcheting sequences than at high temperature. At $10 \mathrm{~K}$, the average vacancy density hardly changes; at $300 \mathrm{~K}$, it increases slightly, whereas at high temperature, the increase in the vacancy concentrations is evident, and grain boundaries act as diffusion paths in the nanocrystalline materials. Unlike the dislocation density, the stress ratio appears to have an impact, and the vacancy population is larger for stress ratio $\mathrm{R}=-0.4$ than for stress ratio $\mathrm{R}=-0.6$.

Table 2: Strains, vacancy, and dislocation densities at the end of each stage for the three temperatures and the two ratcheting stress ratios (where N.A: Not Applicable).

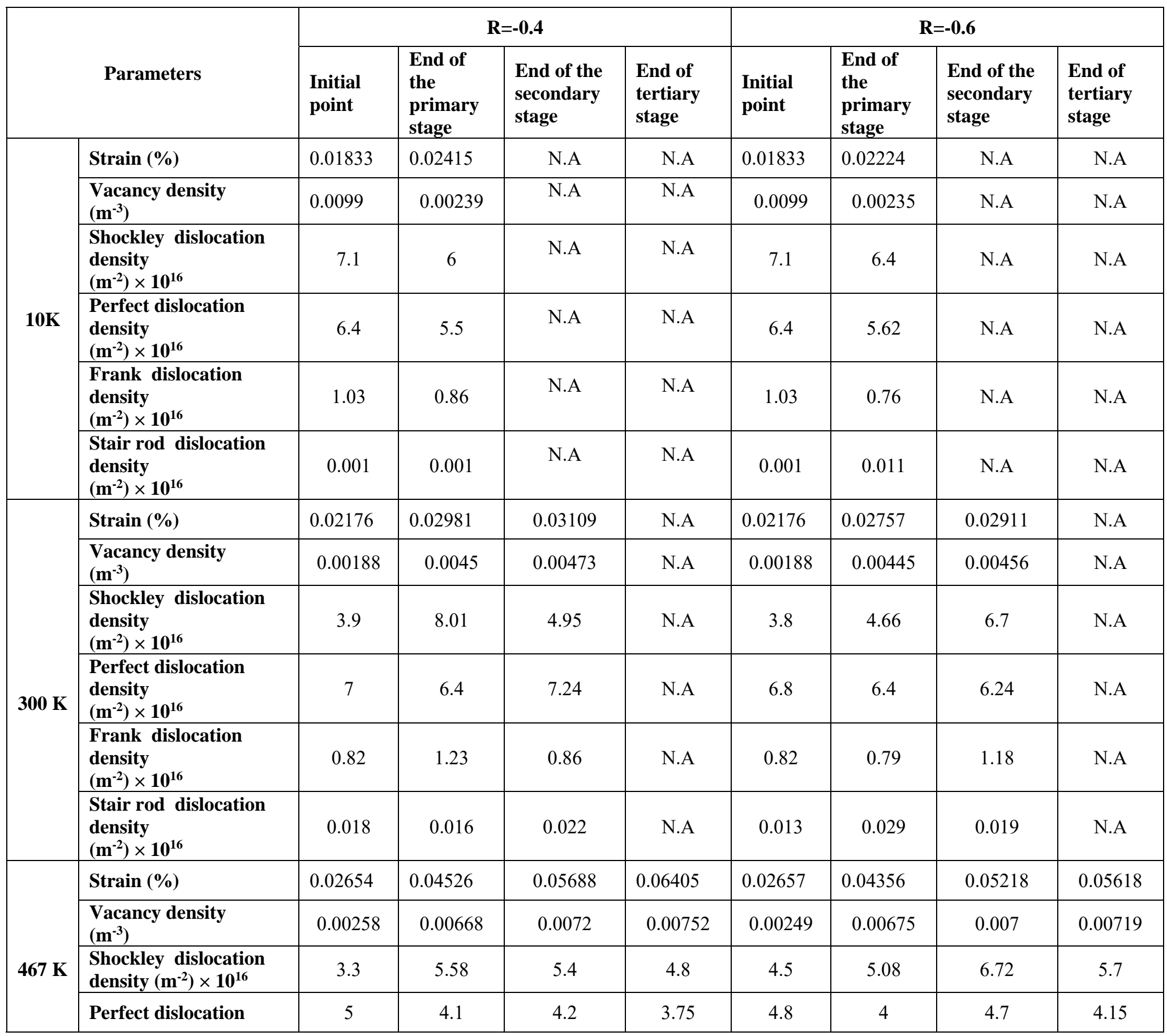




\begin{tabular}{|l|c|c|c|c|c|c|c|c|}
\hline $\begin{array}{l}\text { density } \\
\left(\mathbf{m}^{-2}\right) \times \mathbf{1 0}^{\mathbf{1 6}}\end{array}$ & & & & & & & & \\
\hline $\begin{array}{l}\text { Frank dislocation } \\
\text { density } \\
\left(\mathbf{m}^{-2}\right) \times \mathbf{1 0}^{\mathbf{1 6}}\end{array}$ & 0.6 & 0.69 & 0.69 & 0.59 & 0.73 & 0.71 & 0.76 & 0.62 \\
\hline $\begin{array}{l}\text { Stair rod dislocation } \\
\text { density } \\
\left(\mathbf{m}^{-2}\right) \times \mathbf{1 0}^{\mathbf{1 6}}\end{array}$ & 0.02 & 0.029 & 0.008 & 0.021 & 0.038 & 0.017 & 0.016 & 0.012 \\
\hline
\end{tabular}

\section{Conclusions}

A molecular dynamics simulation-based study has been performed to investigate the creep-ratcheting deformation behavior of nanocrystalline aluminum at three different temperatures $(10 \mathrm{~K}, 300 \mathrm{~K}$, and $467 \mathrm{~K})$. The highest accumulation of creep-ratcheting strain is obtained at the highest temperature after ten creepratcheting deformation cycles. Grain boundary diffusion process is identified as a dominant mechanism for creep ratcheting deformation occurring at room temperature and above. At $467 \mathrm{~K}$, void initiation occurs in the specimen at the early stages and initiates failure. Cyclic hardening in the preliminary stage and cyclic softening in the final stage of creep ratcheting are also observed in the case of high-temperature deformation. We also found that a rise in temperature leads to a reduction in the dislocation density. The results of this study provide a better understanding of the creep-ratcheting mechanism at the atomic-scale. Such knowledge will help extend the improvement in design aspects as well as expand the life of the specimen.

\section{Acknowledgment}

The authors thank the National Institute of Technology Rourkela-computer centre for providing the HPCF (High-performance computing facility) to be carried out these simulations.

\section{Conflicts of interest}

The authors declare that they have no known competing financial interests or personal relationships that could have appeared to influence the work reported in this paper.

\section{Authors Contribution Statement}


All the authors are actively involved in Conceptualization; Data curation; Formal analysis; Investigation; Methodology; Resources; Software; Supervision; Validation; Visualization; Writing - original manuscript draft; Writing - review \& editing.

\section{Data availability}

The raw/processed data required to reproduce these findings cannot be shared at this time because it is a part of an ongoing study. 


\section{References}

[1] Suryanarayana C (1994) Structure and properties of nanocrystalline materials. Bull Mater Sci 17(4):307-346.

[2] Kumar KS, Swygenhoven HV, Suresh S (2003) Mechanical behavior of nanocrystalline metals and alloys. Acta Mater 51:5743-5774.

[3] Meraj M, Pal S (2016) The effect of temperature on creep behaviour of porous (1 at. \%) nano crystalline nickel. Trans Ind Inst Met 69(2):277-282.

[4] Gleiter H (2000) Nanostructured Materials: Basic Concepts and Microstructure, Acta Mater 48(1):1-29.

[5] Suryanarayana C, Koch CC (2000) Nanocrystalline materials - Current research and future directions, Hyp Int 130:5-44.

[6] Meraj M, Yedla N, Pal S (2016) The effect of porosity- and void on creep behavior of ultra-fine grained nano crystalline nickel. Mater Lett 169:265-268.

[7] Ovid'ko IA, Sheinerman AG (2004) Triple junction nanocracks in deformed nanocrystalline materials. Acta Mat 52:1201-1209.

[8] Voyiadjis GZ, Deliktas B (2010) Modeling of strengthening and softening in inelastic nanocrystalline materials with reference to the triple junction and grain boundaries using strain gradient plasticity. Acta Mech 213:3-26.

[9] Pal S, Meraj M (2016) Structural evaluation and deformation features of interface of joint between nanocrystalline $\mathrm{Fe}-\mathrm{Ni}-\mathrm{Cr}$ alloy and nanocrystalline Ni during creep process. Mater Des 108:168-182.

[10] Koch CC (2003) Optimization of strength and ductility in nanocrystalline and ultrafine grained metals. Scr Mater 49(7):657-662.

[11] Fedorov AA, Gutkin MY, Ovid'ko IA (2002) Triple junction diffusion and plastic flow in fine-grained materials. Scr Mat 47(1):51-55.

[12] Mohamed FA, Yang H (2010) Deformation mechanisms in nanocrystalline materials. Metall Mater Trans A $41(4): 823-837$. 
[13] Nie K, Wu WP, Zhang XL, Yang SM (2017) Molecular dynamics study on the grain size, temperature, and stress dependence of creep behavior in nanocrystalline nickel. J Mater Sci 52(4):2180-2191.

[14] Wang YJ, Ishii A, Ogata S (2012) Grain size dependence of creep in nanocrystalline copper by molecular dynamics Mater Tran 53(1):156-160.

[15] Meyers MA, Mishra A, Benson DJ (2006) Mechanical properties of nanocrystalline materials. Prog Mater Sci 51:427-556.

[16] Reddy KV, Meraj M, Pal S (2017) Mechanistic study of bending creep behaviour of bicrystal nanobeam. Comp Mater Sci 136:36-43.

[17] Jiao S, Kulkarni Y (2015) Molecular dynamics study of creep mechanisms in nanotwinned metals. Comp Mater Sci 110, 254-260.

[18] Yamakov V, Wolf D, Phillpot SR, Gleiter H (2002) Grain-boundary diffusion creep in nanocrystalline palladium by molecular-dynamics simulation. Acta Mat 50:61-73.

[19] Ovid'ko IA (2005) Deformation and diffusion modes in nanocrystalline materials. Int Mat Rev 50:65-82.

[20] Yin WM, Whang SH, Mirshams R, Xiao CH (2001) Creep behavior of nanocrystalline nickel at 290 and 373 K. Mat Sci Engg: A 301:18-22.

[21] Kong QP, Cai B, Xiao ML (1997) High temperature creep of two nanocrystalline alloys. Mater Sci Eng A 234:91-93.

[22] Van Petegem S, Brandstetter S, Schmitt B, Van Swygenhoven H (2009) Creep in nanocrystalline Ni during X-ray diffraction. Scr Mater 60(5):297-300.

[23] Lin YC, Chen XM, Chen G (2011) Uniaxial ratcheting and low-cycle fatigue failure behaviors of AZ91D magnesium alloy under cyclic tension deformation. J Alloy Comp 509(24):6838-6843.

[24] Shariatim M, Hatami H, Yarahmadi H, Eipakchi HR (2012) An experimental study on the ratcheting and fatigue behavior of polyacetal under uniaxial cyclic loading. Mat Des 34:302-312. 
[25] Kang G (2008) Ratchetting: recent progresses in phenomenon observation, constitutive modeling and application. Int J Fat 30(8):1448-1472.

[26] Li C, Jaramillo E, Strachan A (2013) Molecular dynamics simulations on cyclic deformation of an epoxy thermoset. Poly 54(2):881-890.

[27] Jiang H, Zhang J, Kang G, Xi C, Jiang C, Liu Y (2013) A test procedure for separating viscous recovery and accumulated unrecoverable deformation of polymer under cyclic loading. Poly Test 32(8):1445-1451.

[28] Zakavi, SJ, Aghaei Y (2020) "The ratcheting behavior of carbon steel piping elbows under cyclic bending moment and temperature." J Bra Soc Mech Sci Eng 42(8): 1-9.

[29] Sreenivasan S, Mishra SK, Dutta K (2017) Ratcheting strain and its effect on low cycle fatigue behavior of Al 7075-T6 alloy. Mater Sci Engg A 698:46-53.

[30] Kreethi R, Verma P, Dutta K (2015) Influence of heat treatment on ratcheting fatigue behavior and post ratcheting tensile properties of commercial aluminum. Trans Ind Inst Met 68:229-237.

[31] Zheng XT, Xuan FZ, Zhao P (2011) Ratcheting-creep interaction of advanced 9-12\% chromium ferrite steel with anelastic effect. Int J Fat 33:1286-1291.

[32] Zheng X, Wen X, Wang W, Gao J, Lin W, Ma L, Yu J (2017) Creep-ratcheting behavior of PTFE gaskets under various temperatures. Poly Test 60:229-235.

[33] Karvan P, Varvani-Farahani A (2020) Uniaxial ratcheting assessment of 304 stainless steel samples undergoing step-loading conditions at room and elevated temperatures. J Eng Mater Tech 142(3): 031003.

[34] Carter P (2005) Analysis of cyclic creep and rupture. Part 2: Calculation of cyclic reference stresses and ratcheting interaction diagrams. Int J Pres Ves Pip 82:27-33.

[35] Yoshida F (1990) Uniaxial and biaxial creep-ratcheting behavior of SUS304 stainless steel at room temperature. Int J Pres Ves Pip 44:207-223.

[36] Chen K, Liu H, Zhang Z, Li S, Todd R (2003) The improvement of constituent dissolution and mechanical properties of 7055 aluminum alloy by stepped heat treatments. J Mater Proc Tech 142(1):190-196. 
[37] Srivatsan TS, Sriram S, Veeraraghavan D, Vasudevan VK (1997) Microstructure, tensile deformation and fracture behaviour of aluminium alloy 7055. J Mater Sci 32(11):2883-2894.

[38] Song Y, Ma Y, Zhan K (2020) Simulations of deformation and fracture of graphene reinforced aluminium matrix nanolaminated composites. Mech Mater 142:103283.

[39] Wang BB, Xue P, Xiao BL, Wang WG, Liu YD, Ma ZY (2020) Achieving equal fatigue strength to base material in a friction stir welded 5083-H19 aluminium alloy joint. Sci Tech Weld Join 25(1):81-88.

[40] Ashkenazy Y, Averback RS (2012) Irradiation induced grain boundary flow - a new creep mechanism at the nanoscale. Nano Lett 12:4084-4089.

[41] Pal S, Mishra S, Meraj M, Mondal AK, Ray BC (2018) On the comparison of interrupted and continuous creep behaviour of nanocrystalline copper: A molecular dynamics approach. Mater Lett 229:256-260.

[42] Yamakov V, Wolf D, Phillpot SR, Gleiter H (2002) Grain-boundary diffusion creep in nanocrystalline palladium by molecular-dynamics simulation. Acta Mater 50:61-73.

[43] Wang YJ, Ishii A, Ogata S (2012) Grain size dependence of creep in nanocrystalline copper by molecular dynamics. Mater Trans 53:156-160.

[44] Pal S, Gururaj K, Meraj M, Bharadwaj RG (2019) Molecular Dynamics Simulation Study of Uniaxial Ratcheting Behaviors for Ultrafine-Grained Nanocrystalline Nickel. J Mater Engg Per 28(8):4918-4930.

[45] Chen D (1995) Structural modeling of nanocrystalline materials. Comput Mater Sci 3(3):327-333.

[46] Li J (2003) AtomEye: an efficient atomistic configuration viewer. Model Simul Mater Sci Eng 11(2):173.

[47] Mendelev MI, Kramer MJ, Becker CA, Asta M (2008) Analysis of semi-empirical interatomic potentials appropriate for simulation of crystalline and liquid Al and Cu. Phil Magz 88(12):1723-1750.

[48] Pan SP, Feng SD, Qin JW (2016) Correlation between local structure and dynamic heterogeneity in a metallic glass-forming liquid. J Alloys Comp 664:65-70.

[49] Nosé S (1984) A unified formulation of the constant temperature molecular dynamics methods. J Chem Phys 81(1):511-519. 
[50] Meraj M, Yedla N, Pal S (2016) Role of W on the dislocation evolution in Ni-W alloy during tension followed by compression loading. Metals Mater Int 22(3):373-382.

[51] Berendsen HJ, Postma JV, van Gunsteren WF, DiNola ARHJ, Haak JR (1984) Molecular dynamics with coupling to an external path. J Chem Phys 81(8):3684-3690.

[52] Plimpton S (1995) Fast Parallel Algorithms for Short-Range Molecular Dynamics. J Comput Phys 117:119.

[53] Stukowski A (2009) Visualization and Analysis of Atomistic Simulation Data with OVITO-The Open Visualization Tool. Modell Simul Mater Sci Eng 18:015012.

[54] Kelchner CL, Plimpton SJ, Hamilton JC (1998) Dislocation nucleation and defect structure during surface indentation. Phys Rev B 58(17):11085.

[55] Honeycutt JD, Andersen HC (1987) Molecular dynamics study of melting and freezing of small LennardJones clusters. J Phys Chem 91(19):4950-4963.

[56] Faken D, Jónsson H (1994) Systematic analysis of local atomic structure combined with 3D computer graphics. Comput Mater Sci 2(2):279-286.

[57] Juslin N, Jansson V, Nordlund K (2010) Simulation of Cascades in Tungsten-Helium. Philos Mag 90(26): $3581-3589$

[58] Nordlund K, Ghaly M, Averback RS, Caturla M, de La Rubia TD, Tarus J (1998) Defect Production in Collision Cascades in Elemental Semiconductors and fcc Metals. Phys Rev B 57(13):7556.

[59] Stukowski A, Bulatov VV, Arsenlis A (2012) Automated identification and indexing of dislocations in crystal interfaces. Modell Simul Mater Sci Eng 20(8):085007.

[60] Li J, Fang Q, Liu Y (2014) Void formation of nanocrystalline materials at the triple junction of grain boundaries. Mat Res Exp 1(1):015013.

[61] Paul SK, Sivaprasad S, Dhar S, Tarafder S (2010) Ratcheting and low cycle fatigue behavior of SA333 steel and their life prediction. J Nucl Mater 401(1-3): 17-24. 
[62] Pal S, Babu PN, Gargeya BSK, Becquart CS (2019) Molecular Dynamics simulation based investigation of possible enhancement in strength and ductility of nanocrystalline aluminum by CNT reinforcement. Mater Chem Phy 243:122593. 